Article

\title{
Satellite Survey of Internal Waves in the Black and Caspian Seas
}

\author{
Olga Lavrova * (D) and Marina Mityagina \\ Space Research Institute of Russian Academy of Sciences, Moscow 117997, Russia; mityag@iki.rssi.ru \\ * Correspondence: olavrova@iki.rssi.ru; Tel.: +7-495-333-4256
}

Received: 30 June 2017; Accepted: 25 August 2017; Published: 28 August 2017

\begin{abstract}
The paper discusses the results of a study of short-period internal waves (IWs) in the Black and Caspian Seas from their surface manifestations in satellite imagery. Since tides are negligible in these seas, they can be considered non-tidal. Consequently, the main generation mechanism of IWs in the ocean-interaction of barotropic tides with bathymetry-is irrelevant. A statistically significant survey of IW occurrences in various regions of the two seas is presented. Detailed maps of spatial distribution of surface manifestations of internal waves (SMIWs) are compiled. Factors facilitating generation of IWs are determined, and a comprehensive discussion of IW generation mechanisms is presented. In the eastern and western coastal zones of the Black Sea, where large rivers disembogue, intrusions of fresh water create hydrological fronts that are able to generate IWs. At the continental shelf edge, on the west and northwest of the Black Sea and near the Crimean Peninsula, IWs are generated primarily due to relaxation of coastal upwelling and inertial oscillations associated with hydrological fronts. In addition, IWs can be formed at sea fronts associated with the passage of cold eddies. In the Caspian Sea, seiches are the main source of the observed IWs.
\end{abstract}

Keywords: Caspian Sea; Black Sea; internal waves; satellite remote sensing; sea surface; SAR imagery

\section{Introduction}

Internal waves (IWs) exist in the stably stratified ocean which corresponds to water density increase in the direction of gravity force. They are wave-like oscillations of water particles around a stable equilibrium position under the restoring action of Archimedes (buoyancy) forces [1]. IWs are characteristic of the dynamics of all density-stratified water bodies-oceans, seas, lakes and reservoirs. The differences in layer densities may be caused by differences in water temperature or salinity. In fact, such processes also occur at the air/water interface. Unlike surface waves, IWs entrain fluid particles that undergo vertical displacements with maximum amplitude located deep in water rather than at the surface. At the same time, maximum amplitudes of horizontal displacements (orbital motion in IW) are found in the immediate proximity to the ocean surface where these amplitudes can reach almost $1 \mathrm{~m} / \mathrm{s}$ and produce perceptible changes in small-scale wind wave spectrum [2].

IWs are known to strongly affect processes in the ocean. Motions induced by IWs transpierce the whole body of ocean water and also play an important role in processes at its surface. They can propagate over several hundred kilometers and transport both mass and momentum. IW propagation is accompanied by a considerable velocity shear that can lead to turbulence and mixing. That is why IWs, and mechanisms of their generation, development, propagation and decay are always a research focus.

With the employment of synthetic aperture radars (SARs), satellite remote sensing techniques provided a new outlook for the study of oceanic IWs [3]. Satellite observations of surface manifestations of internal waves (SMIWs) enable determining their spatial parameters and regions of regular occurrence, as well as analyzing possible generation mechanisms and evolution. Today, using SAR data 
in IWs studies is standard practice around the world. By the initiative of John Apel, an atlas of surface manifestations of IWs has been created and is maintained [4], presently comprising over 300 instances of IW patterns from 54 regions of the world. Hundreds of publications have been devoted to remote sensing of IWs and the flow of works does not seem to run out. For example, the development of remote-sensing techniques in the study of IWs as well as the internal wave studies in the South China Sea were summarized in [5]. Single or a series of SAR images makes it possible to investigate the two dimensional structure of IWs by determining such characteristics as: half-width, crest length, number of waves, propagation direction, distance between neighboring trains, distance between neighboring IWs, and wave velocity. By using these IW parameters in models, oceanographers have been able to derive important physical information, such as oceanic mixed layer depth [5-15]. However, most of the observations concern IWs generated by tidal currents in shelf zones. It is widely accepted that IW generation is closely related to tidal activity. Specifically, tidal IWs occur as a result of tidal currents flowing normal to the local bathymetry features. Such processes are statistically reproducible, given the same season, the same phase of both daily and fortnightly tides, and the same bathymetry. That is why most remote sensing techniques are tailored for studying IWs generated by tidal currents and internal tides in shelf zones.

By contrast, IWs of non-tidal origin have received much less attention. In non-tidal seas, IWs can be induced by intensive dynamic processes such as coastal upwelling, eddies, wind-driven water movements, hydrological front oscillations, etc. There are some works based on contact methods focused on observation and numerical modeling of generation and propagation of non-tidal IWs [16,17]. However, publications on satellite observation of IWs in non-tidal seas are scarce and focus mainly on IWs in large lakes [18-20].

Up to date, there are no reports on studies of IWs in the Black and Caspian Seas based on their manifestations in satellite images, with the exception of publications by the researchers of Space Radar Laboratory of the Space Research Institute RAS, where the authors belong. Our works, initially performed for the northeastern Black Sea and Middle Caspian, revealed a variety of IW types which could possibly be explained not only by bottom topography features, but also a diversity of generation mechanisms. Preliminary results were presented in international conferences and published in Russian language scientific journals [21-25]. Soon it became clear that IWs in non-tidal seas differed substantially from those generated by barotropic tides on oceanic shelf and their investigation was a challenge. Reconstruction of a satisfactory picture of generation, propagation and interaction of IWs in the seas without tides and validation of IW generation hypotheses demanded accumulation of a large bank of data. In this paper, we summarize the results obtained over a 10-year survey of the Black and Caspian Seas using satellite data. The large amount of examined data permitted some generalizations and statistically significant results on spatial and temporal variability of various SMIWs in satellite images. Factors facilitating generation of non-tidal IWs were determined based on joint analysis of available satellite remote sensing data of the sea surface in microwave, visible (VIS) and near-infrared (NIR) ranges complemented by results of in-situ measurements.

During our long-term monitoring of the Black and Caspian Seas [21], we came across a significant number of SMIWs in satellite imagery. Tides are so negligible in these seas that they cannot induce IWs [26].

The main goal of our work reported in this paper was to broaden our insights into the physics and geography of IWs in non-tidal seas based on satellite data.

This goal implied the following primary tasks: (1) identify regions of non-tidal seas where SMIWs are regularly detected; (2) investigate features of SMIWs based on satellite data in various ranges of the electromagnetic spectrum (microwaves, VIS); (3) determine the reasons for considerable interannual, seasonal and spatial variations in SMIWs both at the sea surface and in radar images of the surface; (4) map SMIWs in the Black and Caspian Seas; and (5) determine probable generation mechanisms of IWs from joint analysis of satellite observations, hydrometeorological data, and in-situ measurements. 
Note that over the past year, new satellite data have emerged ensuring a much higher degree of quality of remote observation of IWs. We refer to the continual flow of various high resolution satellite data from the sensors installed on board new Sentinel satellites launched by European Space Agency. Hence, the possibilities are open to: (1) consider smaller scales since data with resolution of units of meters are now available; (2) compare radar and optical data obtained almost simultaneously in same region and at same high resolution; and (3) investigate IW development and propagation in time due to smaller intervals between the observations.

\section{Study Areas}

\subsection{The Caspian Sea}

The Caspian Sea has no natural connection with the World Ocean and is the largest inland body of water in the world. It contains about 3.5 times more water, by volume, than all five of North America's Great Lakes combined. The Caspian is a lake by geographical definition but it is a saltwater lake. Average salinity of the Caspian Sea water is $12.85 \%$ and that is approximately three times lower than salinity of ocean. The Caspian has characteristics common to both seas and lakes, but its size, hydrometeorological conditions, currents, water level oscillations, flora and fauna are more characteristic of seas [27]. It is basically considered a non-tidal sea since tide heights do not exceed $12 \mathrm{~cm}$ at the coastline and $2 \mathrm{~cm}$ in open sea. Nevertheless, IWs do occur here and their generation mechanisms can be explained by some specific characteristics of this water basin (Figure 1):

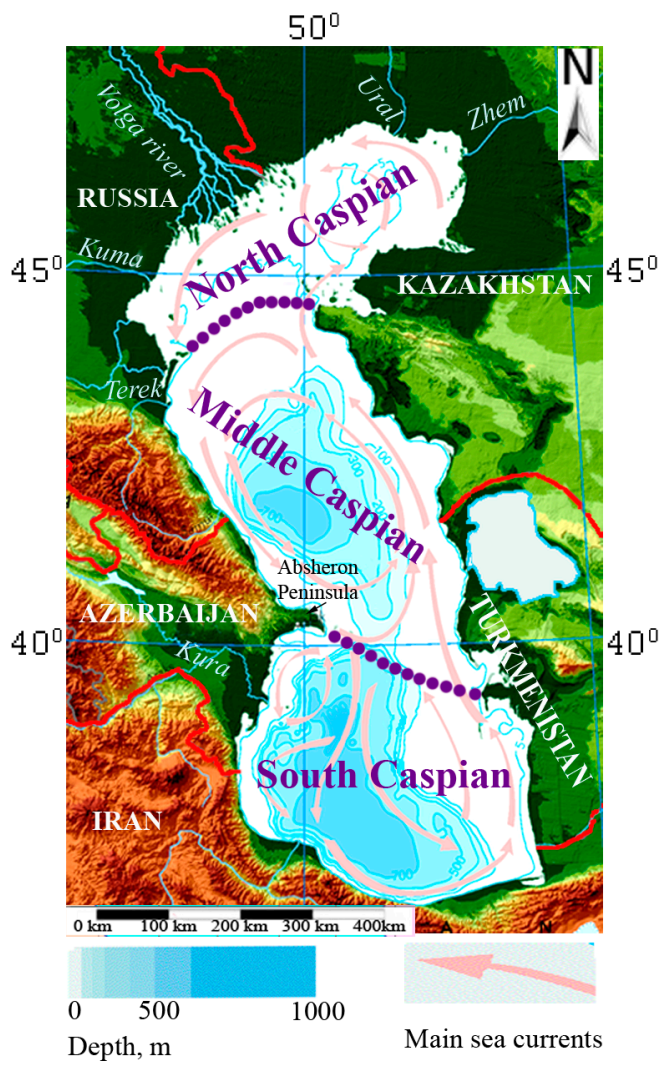

Figure 1. Map of the Caspian Sea. Dots indicate the division into North, Middle and South Caspian.

- The Caspian Sea is divided into three, approximately equal, parts: North, Middle and South.

- The most characteristic features of bottom topography are big shallow water areas in North, and deep areas in Middle and South Caspian. 
- The temperature regime of the Caspian Sea is rather unusual. On the one hand, it is characterized by considerable differences in wintertime temperature between North and South, and, on the other hand, by equalizing the temperatures in summertime. Seasonal oscillations of water temperatures are more pronounced in Middle Caspian. In North Caspian, there is no water temperature stratification due to its shallowness.

- The most typical hydrometeorological feature of the Caspian Sea is the winds that induce 8-10 m high and up to 100-150 m long strong waves throughout November to March in Middle Caspian.

- Well-pronounced atmospheric-forced motions are common. Seiches-like oscillations (amplitudes up to $35 \mathrm{~cm}$, periods from 8-10 min to several hours) occur often [28]. The currents are primarily wind-generated. Horizontal dynamics is characterized by predominating cyclonic circulation at the sea center and by generation of separate local eddies [29].

\subsection{The Black Sea}

The Black Sea is an inner enclosed sea on the southeast of Europe. As part of the Atlantic Basin, it connects to the ocean on the south via the Mediterranean Sea through the Bosporus, Dardanelles and Gibraltar (Figure 2). On the northeast, it connects to the Azov Sea through the Kerch Strait. The total area of the sea is about 422 thousand $\mathrm{km}^{2}$, coastline is $3400 \mathrm{~km}$ long, average depth is $1240 \mathrm{~m}$, and maximum depth is $2210 \mathrm{~m}$. Like the Caspian Sea, the Black Sea is considered non-tidal since tide levels do not exceed $0.1 \mathrm{~m}$ because Mediterranean tides subside in the straits and the Black Sea is not big enough to develop considerable tides of its own. The level of the sea changes primarily due to wind-driven and seiche oscillations, as well as river outflows. Seiches are common in the Black Sea with periods of several minutes to two hours and level oscillations of $0.4-0.5 \mathrm{~m}$, sometimes up to $1 \mathrm{~m}$. The seiche lifetime varies in a broad range: from rapid subsiding to persisting for several days [30].

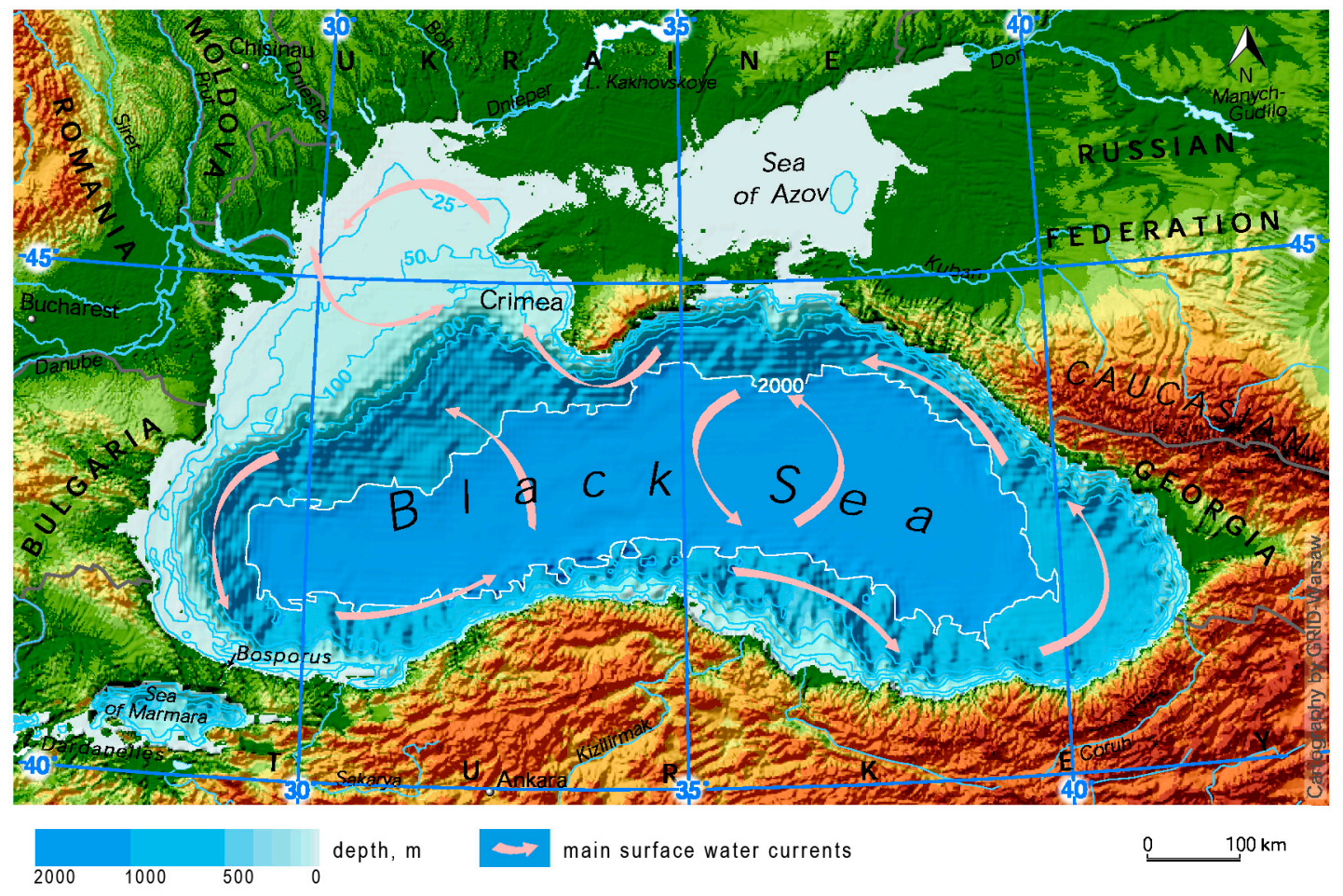

Figure 2. Map of the Black Sea.

The continental shelf of the Black Sea has a slight inclination (to the depths of 100-150 m) over the distance of a few kilometers off mountainous coasts. It ends with an abrupt (up to $20^{\circ}-30^{\circ}$ ) slope to the depth of more than $1000 \mathrm{~m}$. The only exception is the northwest of the sea where the shelf is up to $190 \mathrm{~km}$ wide. 
The basic circulation in the Black Sea is characterized by a strong cyclonic basin-wide current along the coastline which is referred to as the Rim Current [31,32]. It is highly hydrodynamically unstable and consists of a system of moving mesoscale rings and eddies [21,33]. Eddies of various scales are typical of the whole coastal zone of the Black Sea $[2,23,34,35]$. The hydrological regime of the sea is determined by water exchange with the Marmora and Azov Seas, inflow of coastal fresh waters and climatic conditions. Coastal waters significantly freshen the near-surface water layer. The major part of river water (up to $80 \%$ ) flows in on the northwest, where the largest rivers, Danube, Dnepr and Dniester, disembogue. On the east, rivers Inguri, Rioni, and Chorokh as well as many smaller ones carry their waters into the sea. Along the rest of the coastline, the inflow of coastal waters is insignificant [30].

All year round, the temperature of the near-surface layer of water tends to grow in the direction from northwest to southeast which is conditioned by the regional climate. In coastal zones, water temperature is strongly influenced by storm surges and upwellings. Negative storm surges or upwellings occurring near the Crimean Peninsula (Crimea) and the east coast in summer were reported to drop the near-surface water temperature from 25 to $7^{\circ} \mathrm{C}[30]$.

\section{Data and Methods}

\subsection{Data and Data Processing}

Data were processed and analyzed using the toolkit of the satellite information system developed at Space Research Institute of the Russian Academy of Sciences (IKI RAS). The system is named "See the Sea" (STS). STS functionality, goals and current status are detailed in [36,37]. STS provides not only instruments for fast and easy access to satellite data and products, but also various tools for specialized data analysis. In addition, it enables joint analysis of data different in nature, spatial resolution, unit of measurement and acquisition time. The archive of STS is constantly automatically updated by its data receiving unit communicating with a number of data source centers. Today, it holds over 100,000 individual scenes. STS enables easy search of the distributed image archive using sensor type, time interval and location as search criteria. The selected image is visualized in the map area of the interface along with its geographic basis and related cartographic data. All information (regardless of sensor type or product) is presented for viewing in the same cartographic projection for a given geographic area. This facilitates data selection for analysis. Combining data of different nature (active/passive microwave, VIS and NIR), spatial resolution and swath width allowed us to better understand the complex picture of meteorological and hydrodynamic processes in the study regions, reveal factors favoring generation of non-tidal IWs, and, consequently, come up with a hypothesis on generation mechanisms.

For purposes of complex analysis, STS has a specialized cartographic web-interface allowing researchers to search, process and analyze various remote sensing data and related (for instance, meteorological) information.

Our investigation of IWs in the Black and Caspian Seas began with selecting satellite data required for the reconstruction of IWs generation and propagation in the regions of interest. After expert visual identification of SMIWs in satellite images, the images were processes and analyzed. This could include image contrasting, conversion into different units, comparison of images of different acquisition times, creating color composites using different bands and data types (including data acquired at different times), as well as parameter estimation of different objects, pixel-by-pixel analysis for various products, etc.

]Using the STS interface, the main characteristics of IWs were determined in an interactive semi-automatic mode. The result was a comprehensive description of the phenomena, including: the train's center coordinates, water depth at the manifestation location, number of waves in the train, its width, maximal wave length in the train, direction of propagation, presence of nonlinear interactions, near-surface wind speed and direction. The description was stored in the database. The database tools allow storing and visualization of graphical and attributive information, hierarchical classification of 
observed processes, search by spatial, time and typological criteria, and mapping IWs distribution in the studied seas.

\subsection{Basics of SMIWs in Sea Surface Radar Imagery}

Case studies performed during numerous field experiments have revealed main characteristics of IWs in oceans and seas. They propagate in trains, usually rank-ordered, with the largest, the fastest, the greatest-wavelength, and the longest-crested oscillations appearing at the train front. The maximal amplitudes of fluid particles' vertical displacements in IW occur at the pycnocline (the layer of rapid vertical changes in water column density), while the maximal amplitudes of horizontal displacements and horizontal orbital velocities are observed at the sea surface and may reach tens of $\mathrm{cm} / \mathrm{s}$, substantially modulating small-scale wind waves [38]. SMIWs usually look as alternating parallel bands of enhanced and attenuated surface roughness. The resulting surface roughness variations are translated into contrast variations in radar data [39]. SMIWs are made visible in SAR data due to: (i) associated with IW orbital currents which modulate, in one way or another, the short surface wave spectra; and (ii) surface films that cause changes in surface tension.

The pertinent theory used in analyzing and interpreting SAR data includes a few mechanisms of IW effects on the disturbed sea surface due to modulation of short wind gravity-capillary waves. Historically, the first one was a kinematic model based on the wave action balance equation $[2,40]$. It described the significant features of IW-induced modulations of ocean surface observed in early satellite data and explained image contrasts in the case of relatively long electromagnetic waves (tens of centimeters and longer). Two hypotheses based on the Bragg resonant backscatter were suggested to account for the contrasts observable in the range of centimeter waves: the cascade mechanism of ripple modulation based on the known fact that a nonlinear IW can generate "parasitic" capillary ripples near its crest in a resonant manner [41,42], and the mechanism of modulation of the momentum flux towards the surface [43]. Further non-Bragg mechanism of microwave scattering on the SMIWs was studied in [44-47]. Respective quantitative contributions of micro-breaking of steep surface waves in the convergence zones to electromagnetic wave scattering were evaluated in these studies and it was shown that, under certain conditions, they can be very important.

Modulation of centimeter- and decimeter-scale surface waves caused by redistribution of surface films by currents within IWs can also be the dominant factor behind SMIWs imaged by SAR operating in short centimeter wavelengths. Elongated areas with increased film concentrations are present on the sea surface at IW depressions resulting in significant attenuation of ripples and formation of slicks. Since increased surfactant concentration is common for semi-enclosed and inland seas, this mechanism is expected to predominate in such regions $[48,49]$.

Under moderate viewing angles implemented in satellite SARs, SMIWs can be distinctly visualized in co-polarized SAR images on both VV- and HH-polarizations. Co-polarized SAR images are extensively employed in this study.

Figure 3 presents images taken by Advanced Synthetic Aperture Radar (ASAR) on board Envisat satellite and illustrates two different mechanisms of SMIWs in radar imagery. Figure 3a features parallel bands of enhanced backscatter alternating with wide zones of slightly attenuated signal and shows no signs of surfactant film. By contrast, Figure $3 \mathrm{~b}$ depicts long narrow parallel bands of slicks due to concentrated film trapped by a SMIW. The inset graphs show variations in radar signal along the cross sections of the trains (white lines).

Combined analysis of satellite radar and VIS/NIR data is effective for resolving ambiguities in interpretation of radar data, detecting SMIWs, as well as revealing sources and mechanisms of IW generation. VIS/NIR data, especially obtained with sun glint, can provide additional information on the processes and phenomena on the sea surface at low winds. In these conditions, the returned radar backscatter is low, and the surface may appear featureless and uniformly dark across the radar image. Sun glint is observed by optical (VIS/NIR) sensors when sunlight incidence angle is equal to the angle of reflection. Surface roughness excites tilting of numerous small wave facets reflecting sunlight at 
a variety of different angles. Size and shape of a sun glint pattern depend on the probability distribution of the slopes of the facets, incident sunlight direction and sensor viewing angle. Thus, differences in sea surface roughness variance in a sun glint area are manifested as variations in image brightness. An example of SMIW imaged by an optical multispectral sensor is shown in Figure 4c.

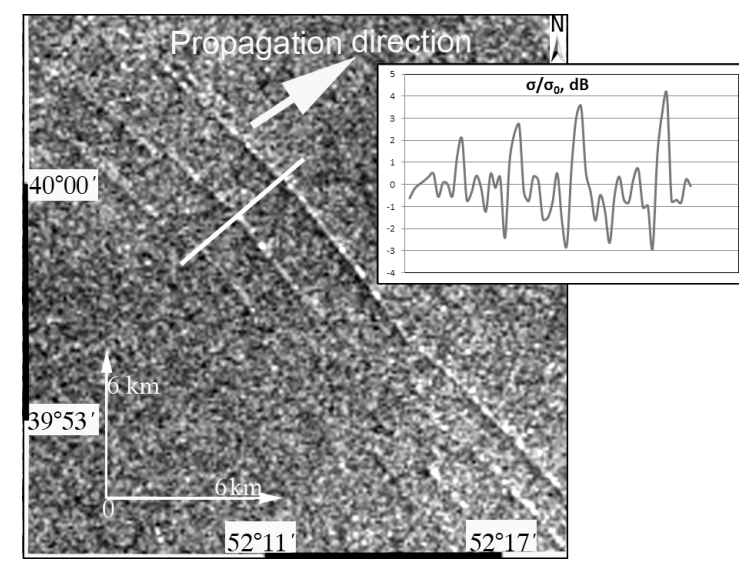

(a)

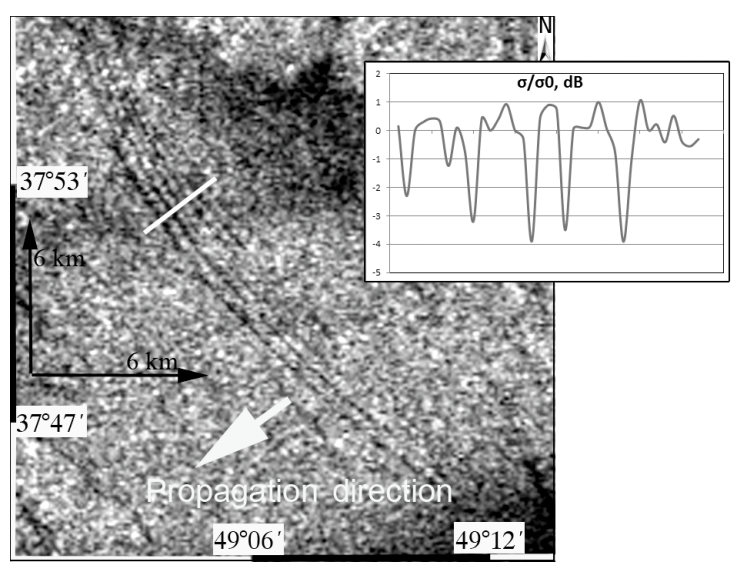

(b)

Figure 3. Mechanisms of Surface manifestations of internal waves imaging by SAR in the Caspian Sea: (a) restructuring of ripple spectrum, Envisat ASAR, HH-polarization, 16 July 2010, 06:44 UTC; and (b) redistribution of surface films, Envisat ASAR, HH-polarization, 26 May 2011, 06:59 UTC.

\section{Results}

\subsection{Radar Observations of IWs in the Caspian Sea}

\subsubsection{Parameters of IWs Derived from Satellite Data}

Numerous SMIWs were identified in satellite data obtained over the Caspian Sea [50], some examples are shown in Figure 4. IWs may appear as isolated solitons, such as the one in Figure 4a. It has a wave length of $900 \mathrm{~m}$ and a wave crest length of $56 \mathrm{~km}$ and propagates southeast. However, the majority of IWs look like classical soliton trains (Figure $4 \mathrm{~b}$ ). The inset depicts variation of the radar signal due to the SMIW along the marked cross section (white line). The leading wave crest is about $68 \mathrm{~km}$ long and the maximal wave length in the train is $1500 \mathrm{~m}$. Sometimes, one image manifests several IW trains that propagate at different angles to each other and interact nonlinearly. In a false-color Landsat-8 OLI image (Figure 4c), five IW trains propagating over the depths of 100-150 m are clearly visible (A, B, C, $\mathrm{D}$, and $\mathrm{E}$ ). The most distinct trains, A, B and C, propagate northeast, the distance between A and B is $9 \mathrm{~km}$, the distance between $B$ and $C$ is $8 \mathrm{~km}$. Each of them contains 4-5 individual waves with average lengths of $350 \mathrm{~m}$, rising intensities from rear to front of a train and leading wave crest lengths of about $55 \mathrm{~km}$. Train D propagates southeast, intersects with $\mathrm{C}$ and $\mathrm{B}$, interacting with them in a nonlinear way. Train $\mathrm{E}$ propagates north, and consists of four waves with leading wave crest length of $15 \mathrm{~km}$ and $400 \mathrm{~m}$ average wave length. The SMIW patterns mimic bottom topography features. Specific curvatures of the leading waves allow for the identification of IW origination areas. They are usually topography inhomogeneities, sandbanks, and steep elevations that are typical of the eastern region of Middle Caspian.

Some statistics on SMIWs in Middle Caspian were derived from the satellite data. Distributions of spatial dimensions of IW trains detected in radar images are shown in Figure 5. The widths of trains varied from 1 to $6 \mathrm{~km}$ depending on the number of waves in train. The length of the longest wave in trains ranged from 150 to $2000 \mathrm{~m}$ (Figure 5a). The lengths of leading wave crests ranged tens of kilometers, between 8 and $80 \mathrm{~km}$ (Figure 5b). 


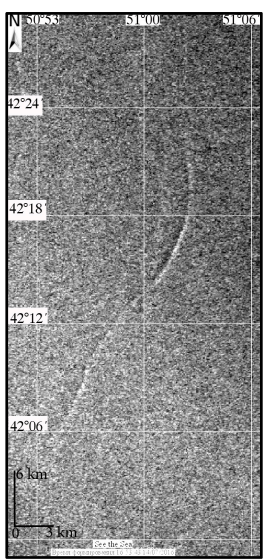

(a)

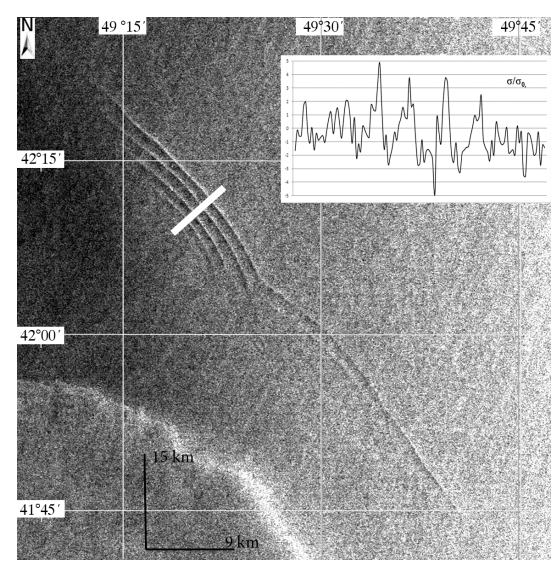

(b)

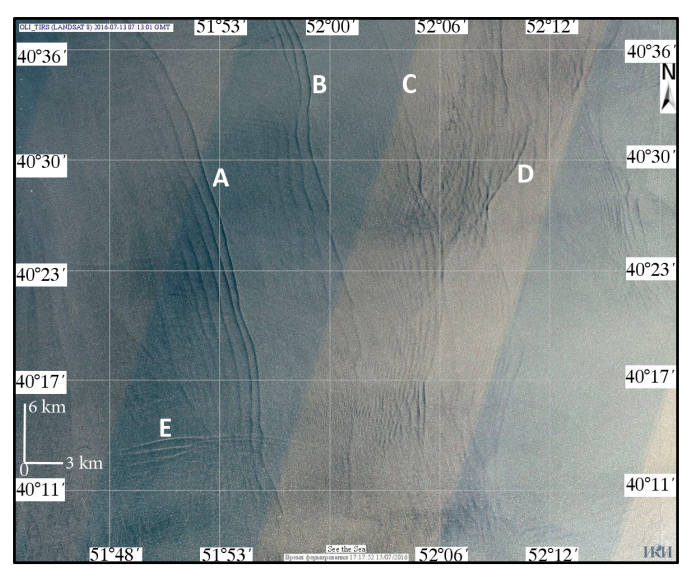

(c)

Figure 4. Surface manifestations of internal waves in the Caspian Sea: (a) Solitary IW, Envisat ASAR, HH-polarization, 25 July 2010, 18:20 UTC; (b) IW train, Envisat ASAR, HH-polarization, 11 September 2010, 06:52 UTC; and (c) Multiple trains of IWs propagating in different directions, Landsat-8 OLI, 13 July 2016, 07:13 UTC.

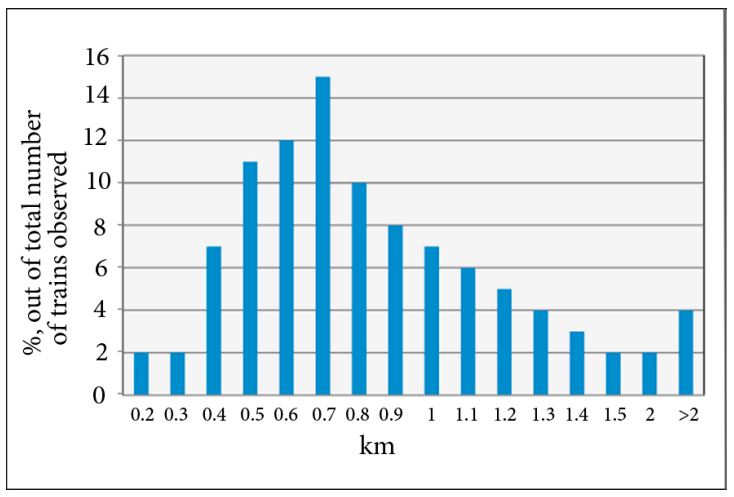

(a)

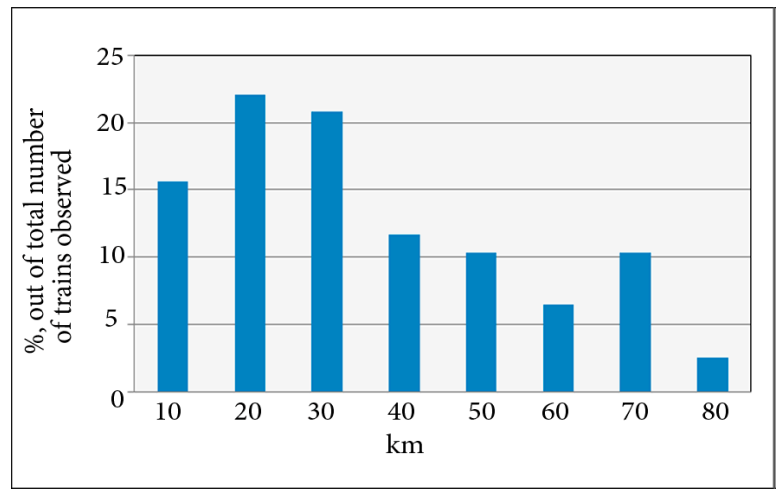

(b)

Figure 5. Distributions of spatial dimensions of IW trains detected in satellite images of the Caspian Sea: (a) maximal wave length in train; and (b) leading wave crest length.

\subsubsection{Spatial and Seasonal Variability of SMIWs in the Caspian Sea}

Spatial distribution of SMIWs in Middle and South Caspian derived from radar data is presented in Figure 6. The data cover only the period from May to October because no IWs were observed throughout the other months.

As can be inferred from Figure 6, the SMIWs are distributed unevenly, concentrating in three main regions. Their occurrence is season-dependent. In the end of May and in the first half of June, SMIWs are found only in the western part of South Caspian (I); in the second part of June and in July, all SMIWs are observed on the east, near the Absheron Sill (II); and in August, they shift northeast (III). By far the largest number of SMIWs is observed in July and August, all located in the eastern Caspian, north of Absheron Sill. In the other parts of the sea, SMIWs occur less often. 


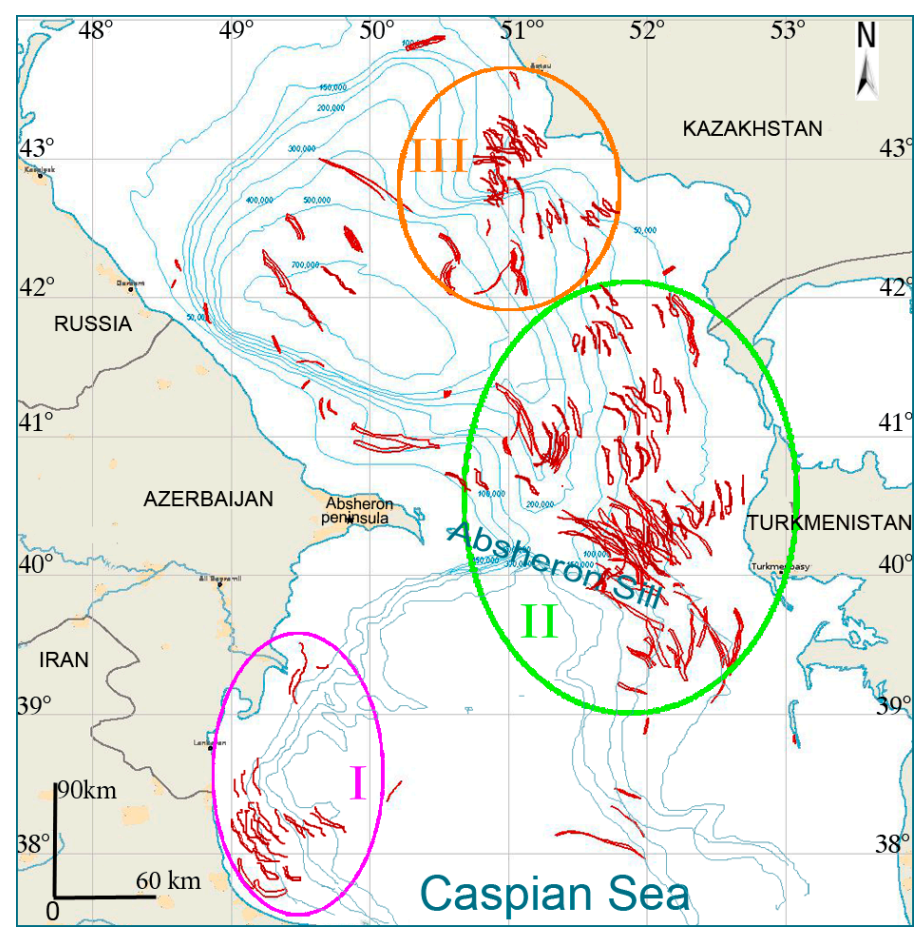

Figure 6. Surface manifestations of internal waves detected in satellite imagery of the Caspian Sea.

\subsection{Satellite Observations of IWs in the Black Sea}

A large archive of radar and VIS/NIR satellite data allowed us to estimate contributions of various factors into generation mechanisms of SMIWs and their spatial distribution in different areas of the Black Sea. There are four main areas in the Black Sea where SMIWs are mostly observed: near the Danube Delta and Crimea on the west, near Novorossiysk on the northeast, and on the continental shelf near Georgia on the east (Figure 7).

\subsubsection{SMIWs near the Danube Delta}

The greatest number of SMIWs is observed on the Romanian shelf, in the area of the Danube Delta. One high resolution satellite image, for example an image acquired by Landsat-8 OLI, with a resolution of $15 \mathrm{~m}$ for the panchromatic band 8 and swath of $185 \mathrm{~km}$, can manifest up to twenty IW trains. Statistical analysis of satellite data shows that SMIWs are mostly observed from May to July in the region. The largest amount of IWs propagating both toward and off the coast was observed in 2010. Most likely, this fact can be explained by specific hydrological conditions of that year. However, no in situ measurements are available to confirm this. Figure 8 shows mapped locations of the leading fronts of IWs revealed in 2010 radar (Envisat ASAR, ERS-2 SAR) and VIS (Landsat-5 TM, Landsat-7 ETM+) images. Orientation peculiarities of the SMIW allow suggesting two main sites the IWs originate from: one is attached to the Danube water plumes (dashed area), while the other is farther off the coast, over the isobaths of 50-75 m.

IWs from the first site propagate in various directions, they contain from 10 to 20 waves with lengths up to $150 \mathrm{~m}$, and their leading fronts are rather distorted. To our view, the source of IWs here is the low-salinity water plumes of the Danube River.

Generation of IWs associated with river outflow is quite common. It is theoretically examined, for example, in [51,52], and satellite observations are described in [53]. Comprehensive measurements of intense IWs induced by an intrusion of low-salinity surface waters were conducted from a marine platform on the northwestern shelf of the Black Sea [54], and numerical modeling based on those data was performed in [55]. These works consider IW generation by a solitary front of estuarine type when wave crests are congruent with the front and propagate to the open sea. 


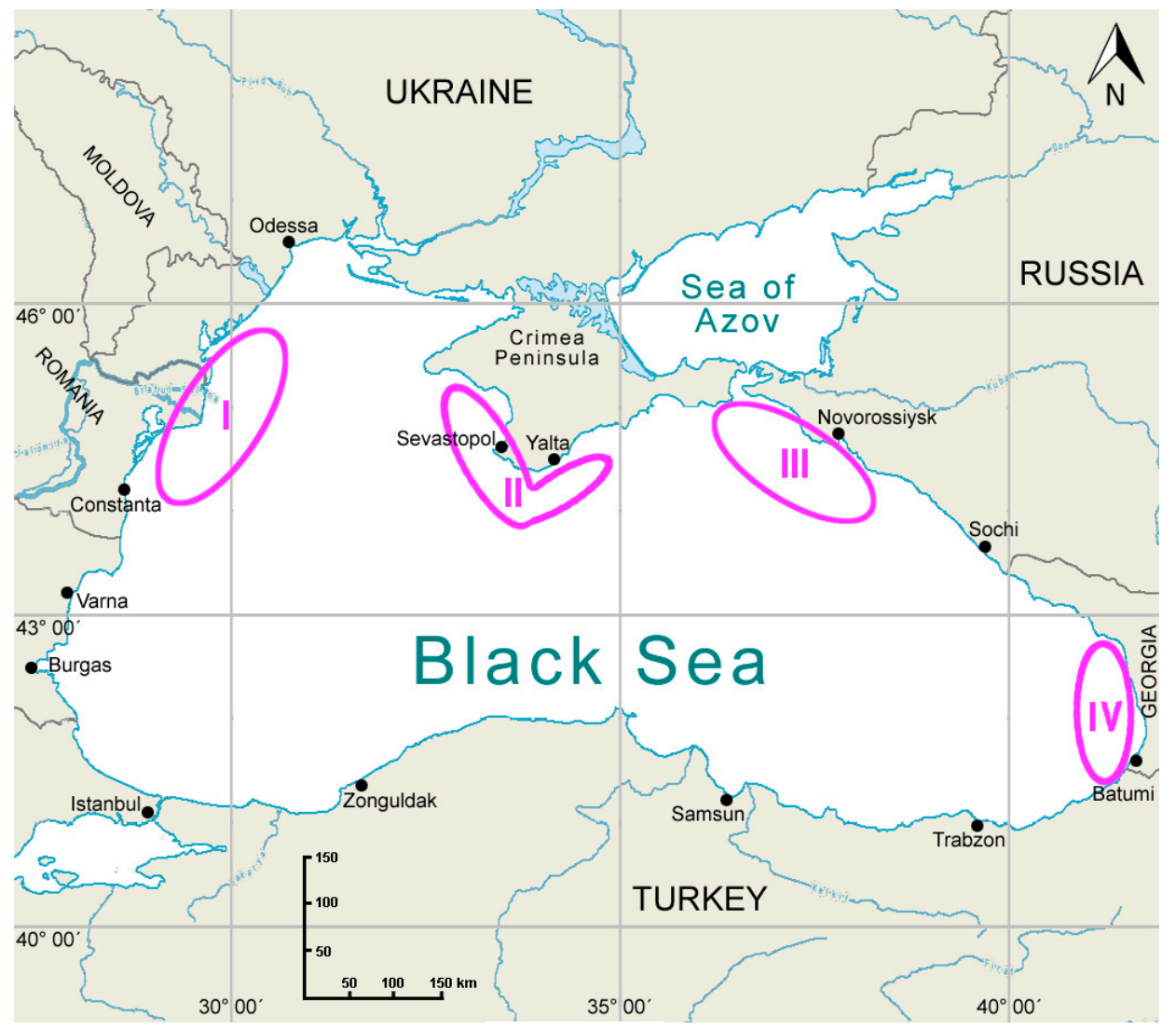

Figure 7. Main areas of SMIWs in the Black Sea, close to: (I) Danube Delta; (II) Crimean Peninsula; (III) city of Novorossiysk; and (IV) shelf of Georgia.

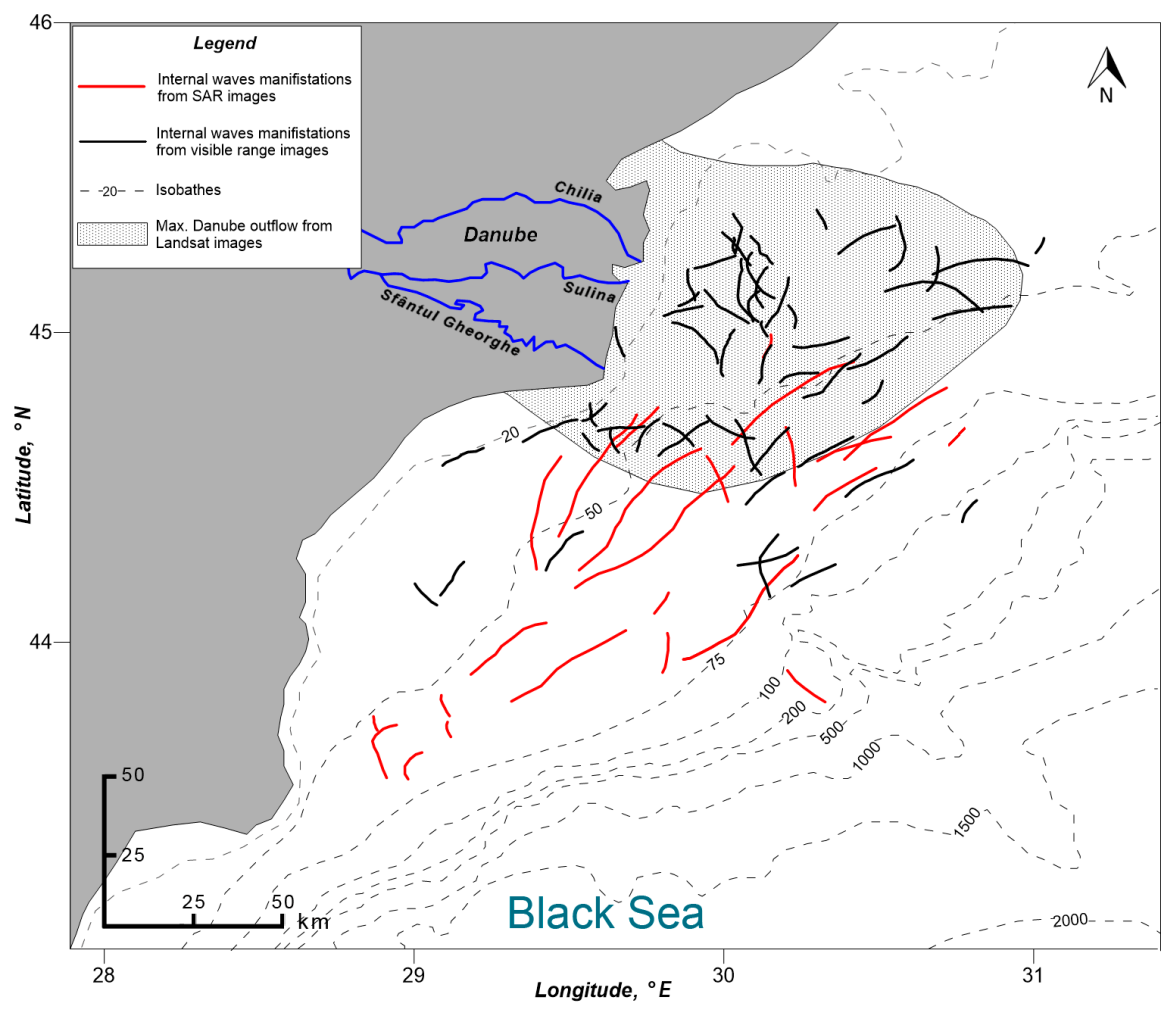

Figure 8. Locations of IW fronts revealed in 2010 satellite data of the Danube Delta region, western Black Sea. 
The Danube waters flow into the surface layer of the Black Sea through many delta arms. The main volume comes via three distributaries: Chilia, Sulina, and Sfântul Gheorghe (Saint George) (Figure 8). In the distributaries, waters have slightly different parameters. Their interaction with each other and the seawater produces multiple relatively small-scale non-stationary fronts, eddies, apparently generating IWs in varying directions. As a rule, the IWs are parallel to the fronts outlining river water plumes of different turbidities.

A color composite of Landsat-5 TM (bands 3, 2, 1, Figure 9) clearly displays turbid fresh Danube waters and multiple (over 20) IWs propagating in different directions. Such direction variability is explained by high non-uniformity of the river outflow as well as bottom topography features. Many IWs sit directly on turbid plume leading fronts so that they propagate together. Multiple IWs cross each other, their fronts become distorted, and new ones occur.

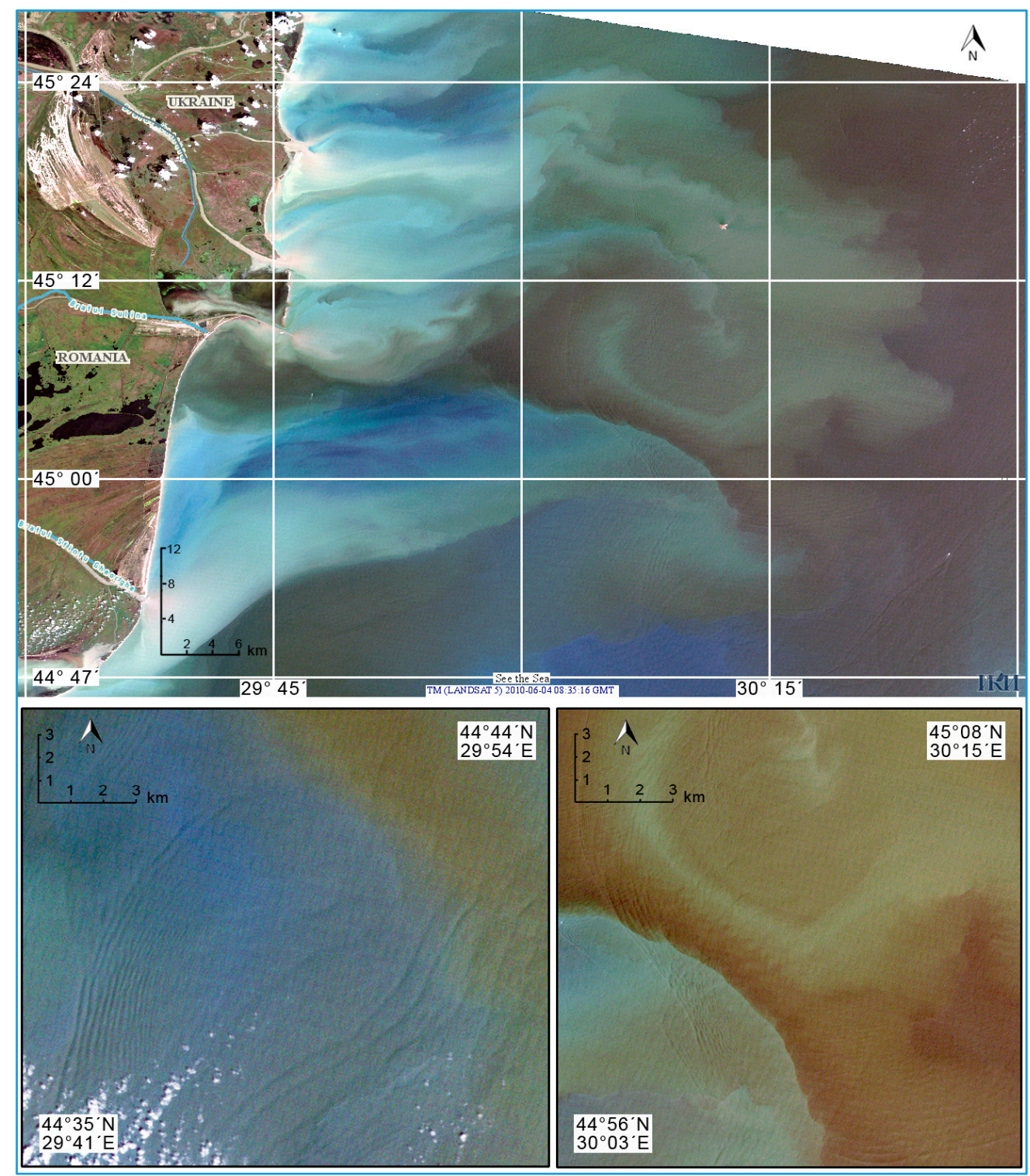

Figure 9. Multiple SMIWs near the Danube Delta. Intense color variation pertains to high turbidity of the Danube plume. Landsat-5 TM (bands 3, 2, and 1), 4 June 2010. 
On the second site (farther off the coast), SMIWs almost always indicate propagation toward the coast with IW fronts parallel to local isobaths. The number of waves in a train usually does not exceed 10, wave length can reach $300 \mathrm{~m}$. The IWs propagate shoreward, being induced, to our view, by inertial period IWs entering the shelf zone, as it occurs in open ocean mainly under the impact of tides. In the Black Sea, the same generation mechanism of intense IWs was also observed near the southern coast of Crimea. Examples of SMIWs imaged by SAR in the second site are shown in Figure 10. To prove our IW generation hypothesis, let us make some estimates in the way shown in $[9,56]$. For the Black Sea, the inertial period is about 17.2 h. From the SAR image in Figure 10, we estimate the distance between the IW trains at $13 \mathrm{~km}$ and, consequently, IW velocity at $0.21 \mathrm{~m} / \mathrm{s}$. The latter value is the characteristic phase velocity of short-period IWs in the Black Sea, which is confirmed by in situ measurements [16]. The periods of waves range 10-20 min by in situ measurements [16,24]. These values are the characteristic periods of intense short period IWs. Thus, the wave length is estimated at 126-252 m, which is in agreement with satellite data. There are no reasons for the IW trains propagating with the front of internal inertial wave to have phase velocity differing from the velocity of the long (inertial) IW.

With known vertical density (Brunt-Väisälä frequency) profile, it is easy to solve the equation for internal inertial waves and obtain estimates of phase velocity and lengths for 17.2-h period and short period waves. For arbitrary profile, the equation can be solved by numerical methods. IW parameters were obtained by a numerical solution of the equation for hydrological conditions of the Danube shelf over the depths of 70-80 m (assuming flat sea floor, which is acceptable for this region). From temperature and salinity profiles measured by Romanian researchers, seawater density was determined and then input into calculations of IW parameters and dispersion characteristics. To simplify calculations, the waves were assumed linear. For $10-\min$ period waves, phase velocity was estimated at $0.42 \mathrm{~m} / \mathrm{s}$, for 20 -min period waves, it was $0.46 \mathrm{~m} / \mathrm{s}$. Wave lengths were $252 \mathrm{~m}$ and $552 \mathrm{~m}$, respectively. Note that, while the lengths of short period waves are of the order of several kilometers in open ocean [9], they are much less in the Black Sea. A good example of a wave train generated by inertial IW on the Black Sea shelf, with wave parameters estimated, is presented in [16].

Nonlinear interactions manifested in Figure 10 were used to estimate the degree of nonlinearity of IWs in the Danube Delta region. The Ursell number $\left(U_{r}\right)$-wave nonlinearity to variance ratio-was calculated with the IWs modeled using the Korteweg-de Vries equation [57]:

$$
U_{r}=(\alpha / \beta) \times c_{0} \times \eta \times \Delta_{s}^{2}
$$

where $\eta$ is wave height, $\Delta_{s}{ }^{2}$ is wave half-width, and $\alpha$ and $\beta$ are nonlinearity and variance coefficients defined in the case of two-layer fluid $\left(H=h_{1}+h_{2}\right)$ as:

$$
\alpha=(3 / 2) \times\left(h_{1}-h_{2}\right) /\left(h_{2} \times h_{1}\right) ; \beta=c_{0} \times h_{1} \times h_{2} / 6
$$

To estimate $\alpha / \beta$ we used hydrological data obtained by Romanian researchers during ship expeditions. The measurements were performed in a time period close to the satellite observations at depths of 25, 55 and $70 \mathrm{~m}$. Water temperature and salinity data were taken at standard depth levels yielding rather coarse vertical profiles of the parameters. Nevertheless, they allowed for a two-layer approximation of the water column [58]. For example for $H=70 \mathrm{M}, h_{1}=15 \mathrm{~m}, h_{2}=55 \mathrm{~m}$. 


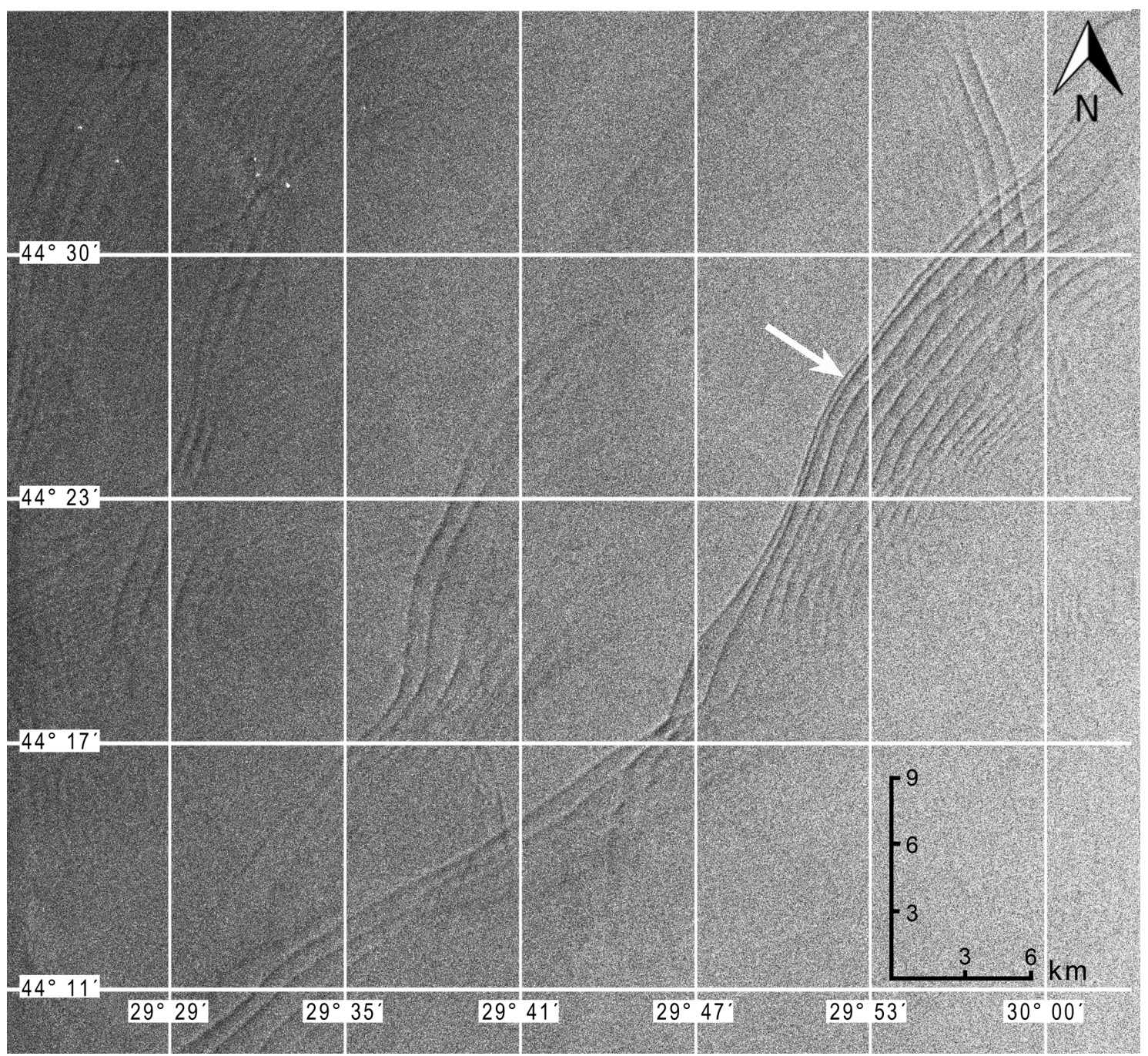

Figure 10. SMIWs near the Danube Delta indicating coastward propagation, Envisat ASAR, VV-polarization, 8 June 2010. Arrow points to the IW train for which the Ursell number was estimated.

Some SMIW spatial characteristics were derived from the image (Figure 10). The one indicated by white arrow has the following characteristics. The train propagates northwest over a wide shelf with a depth about $75 \mathrm{~m}$. There are 14 waves in the train. The front wave is the narrowest one, its length, estimated as the distance between the two successive low-signal bands in the image, is $325 \mathrm{~m}$. The second wave is twice as long- $650 \mathrm{~m}$. Lengths of the following waves are close to this value. At present, it is not possible to estimate IW height from satellite images. Nevertheless, our multi-year experience of measurements in the Black Sea [24] allows us to suggest an estimate of $5 \mathrm{~m}$. For this wave height, $U_{r}$ is assessed at 67.7. If we assume the leading wave height to be $1 \mathrm{~m}$, then $U_{r}=13$, which is close to soliton-type value equal to 12 [59]. This number characterizes the degree of IW field nonlinearity. The higher $U_{r}$, the stronger are nonlinear effects [60]. Considering the obtained $U_{r}$ estimates (13 . 67.7), we can conclude that nonlinearity prevails over variance in IWs propagating towards the coast from open sea in the region of the Danube Delta. 


\subsubsection{IWs near the Crimean Peninsula}

IWs in the region of the Crimean Peninsula have been closely studied and described in detail by researchers of Marine Hydrophysical Institute (Sevastopol) and Acoustics Institute (Moscow). Many results were obtained due to regular observations from a marine scientific platform in Katsiveli (Yalta Region) conducted for the past 30 years; the most recent are presented in [24,61].

We have conducted monitoring of the region since 2009. Until April 2012, we used primarily Envisat ASAR and ERS-2 SAR data, then Landsat data. Starting from October 2014, we have used Sentinel-1 SAR-C data, and since August 2015, Sentinel-2 MSI as well. According to our satellite observations, SMIWs most frequently appear in two areas: near the south and west coasts of Crimea. A typical SMIW near the west coast is shown in Figure 11. The most distinct IW train (another two less pronounced IWs are closer to the coast) propagates east over the depths of 80-90 m, contains 6 waves with an average length of $200 \mathrm{~m}$ and a leading wave crest length about $17 \mathrm{~km}$. All detected IW trains near Crimea propagated toward the coast. Fronts in the trains frequently had the shape of concentric arcs, which made it possible to approximately locate their sources (Figure 12). In this region, at shelf edge, velocity of the Rim Current, the principal element of water circulation in the sea, can reach $1 \mathrm{~m} / \mathrm{s}$ and more. Its meanders and inertial oscillations can induce current components normal to the coastline with velocities up to $50 \mathrm{~cm} / \mathrm{s}$, comparable with current velocities in tidal seas. Another IW generation mechanism involves local hydrological fronts moving over the shelf. For instance, they can be generated by storm surges near south Crimea [16]. Anyways, SMIWs are quite rarely detected in SAR data of the region. During 2009-2011, as few as eight SMIWs were observed, and they occurred not only during June-August, but also in October (for example, 1 October 2010) [34].

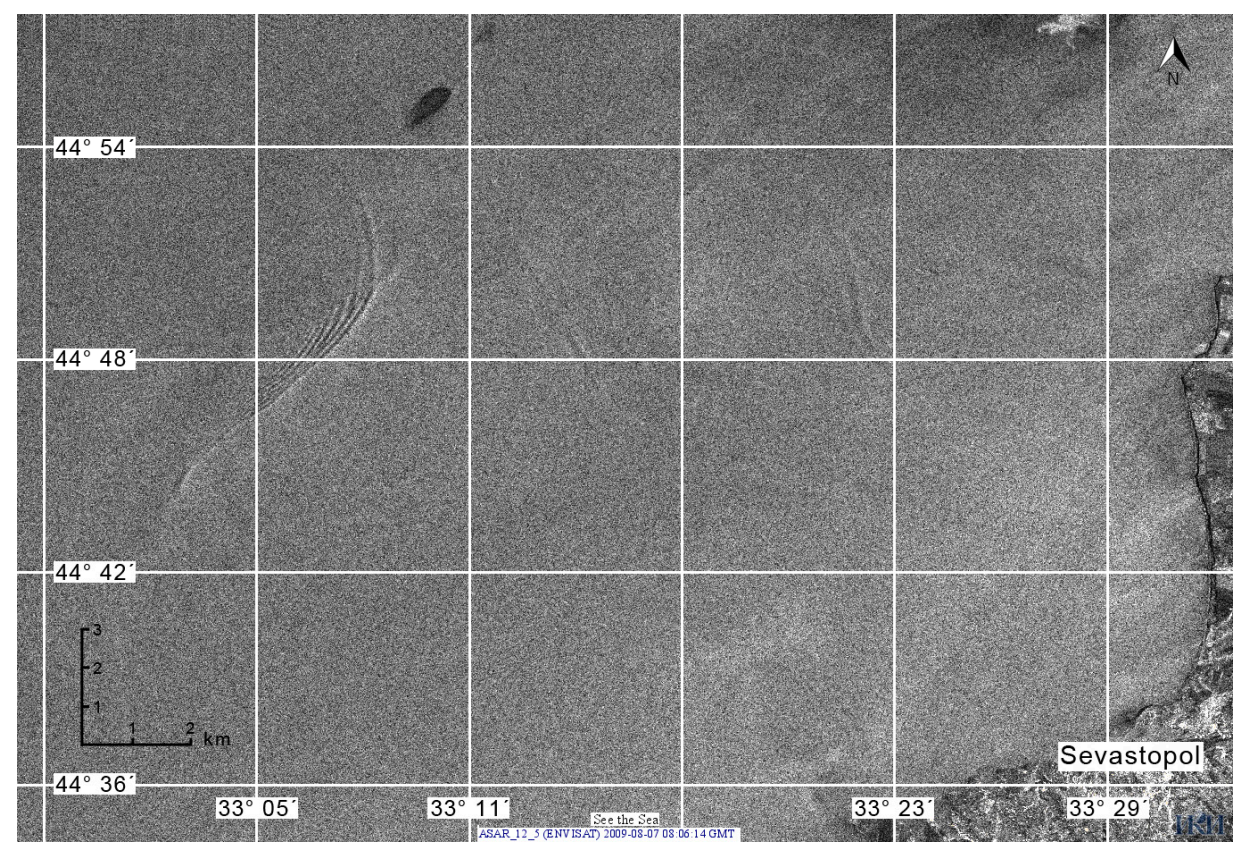

Figure 11. Typical SMIW near the west coast of Crimea, Envisat ASAR, VV-polarization, 7 August 2009. 


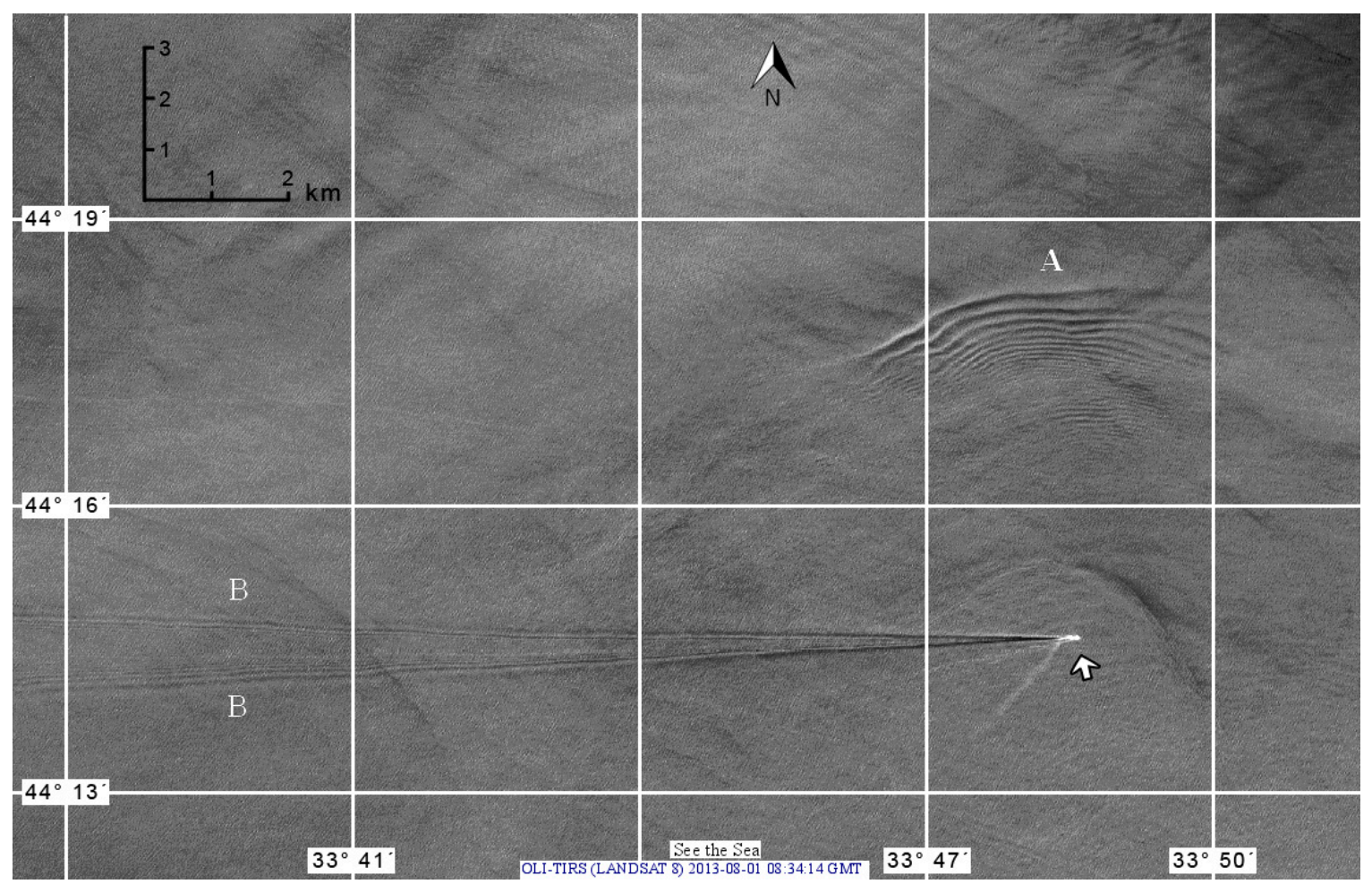

Figure 12. Different types of IWs propagating near the south coast of Crimea: (A) natural IW; and (B) IW generated by a moving ship, arrow points to the ship; Landsat-8 OLI (panchromatic band, resolution $15 \mathrm{~m}$ ), 1 August 2013.

In satellite image of 1 August 2013 (Figure 12) obtained off south Crimea, beside SMIW marked A, we can see two SMIWs marked B. These are IWs generated by a moving ship. Such IWs can be clearly detected in high resolution satellite images obtained by Landsat-8 OLI at a resolution of $15 \mathrm{~m}$ (band 8) or Sentinel 1 and 2 at a resolution of $10 \mathrm{~m}$. Natural (A); and ship-wake (B) IWs in the region have similar wave lengths, about 80-100 m. They obviously differ in crest length, as can be inferred only from satellite data analysis. Natural IW crest length scarcely exceeds 5-6 km, while ship wakes containing IWs can span tens of kilometers. Thus, one may encounter IWs of different origins when interpreting data from regions with ship routes.

\subsubsection{IWs in the Eastern Black Sea}

As mentioned above (Section 2.2), the eastern Black Sea is characterized by a narrow shelf (the $200 \mathrm{~m}$ isobath is at the distance of only $5 \mathrm{~km}$ from the coast) and many rivers carrying waters into the sea. There are important differences between SMIWs on the west (Danube Delta) and east (shelf of Georgia). In contrast to the wide western shelf, no IWs generated at shelf edge were observed on the east. All SMIWs were associated with river plumes. Analysis shows that submesoscale IWs occur due to inertial currents of (always) unstable sharp plume boundary front. IWs of this type are manifested only in high resolution data and are best pronounced in VIS images. Examples are presented in Figure 13. Wave length in the trains does not exceed $50 \mathrm{~m}$, the length of leading wave crest depends on the shape of river plume. The seasonal character of these SMIWs is associated with variations in river outflow volumes rather than thermocline behavior. 


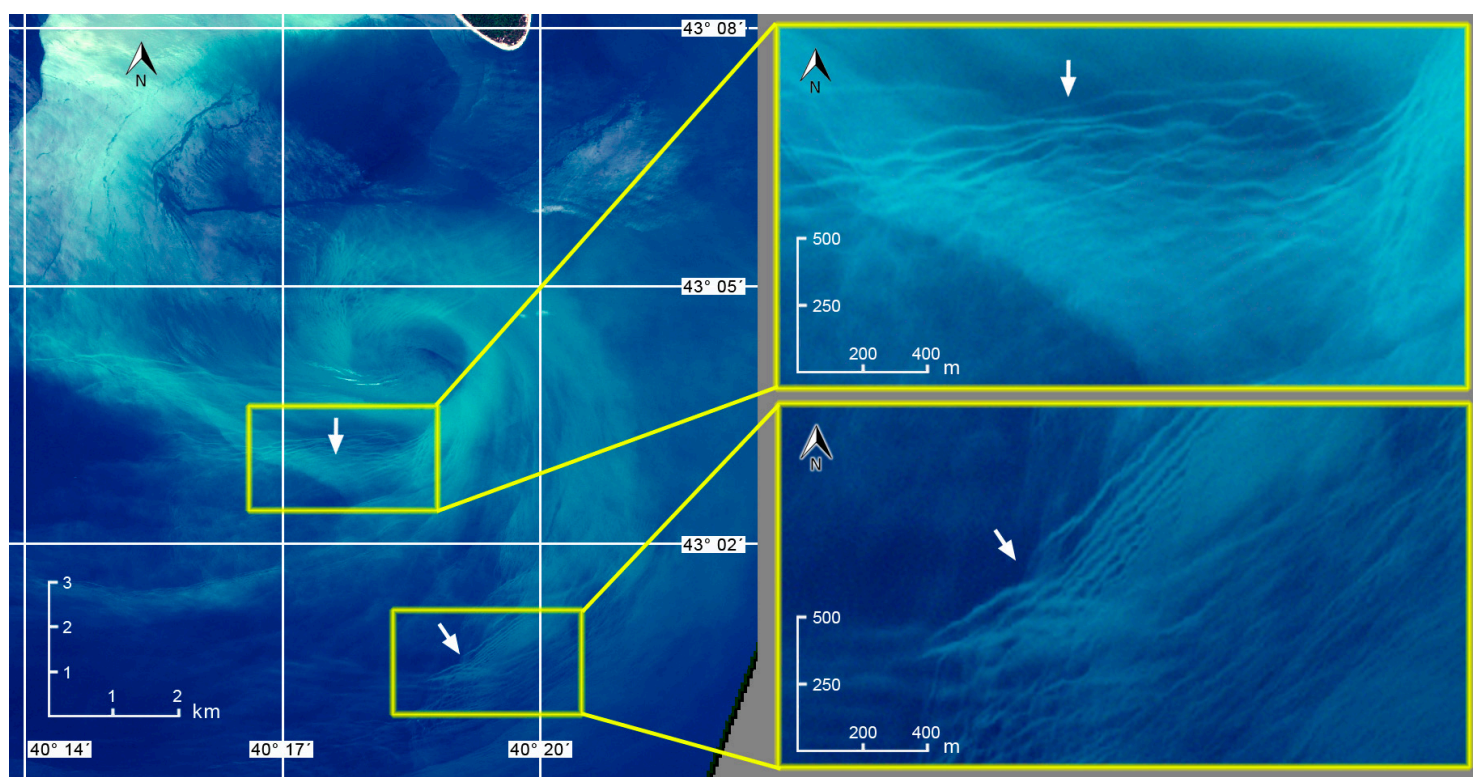

(a)

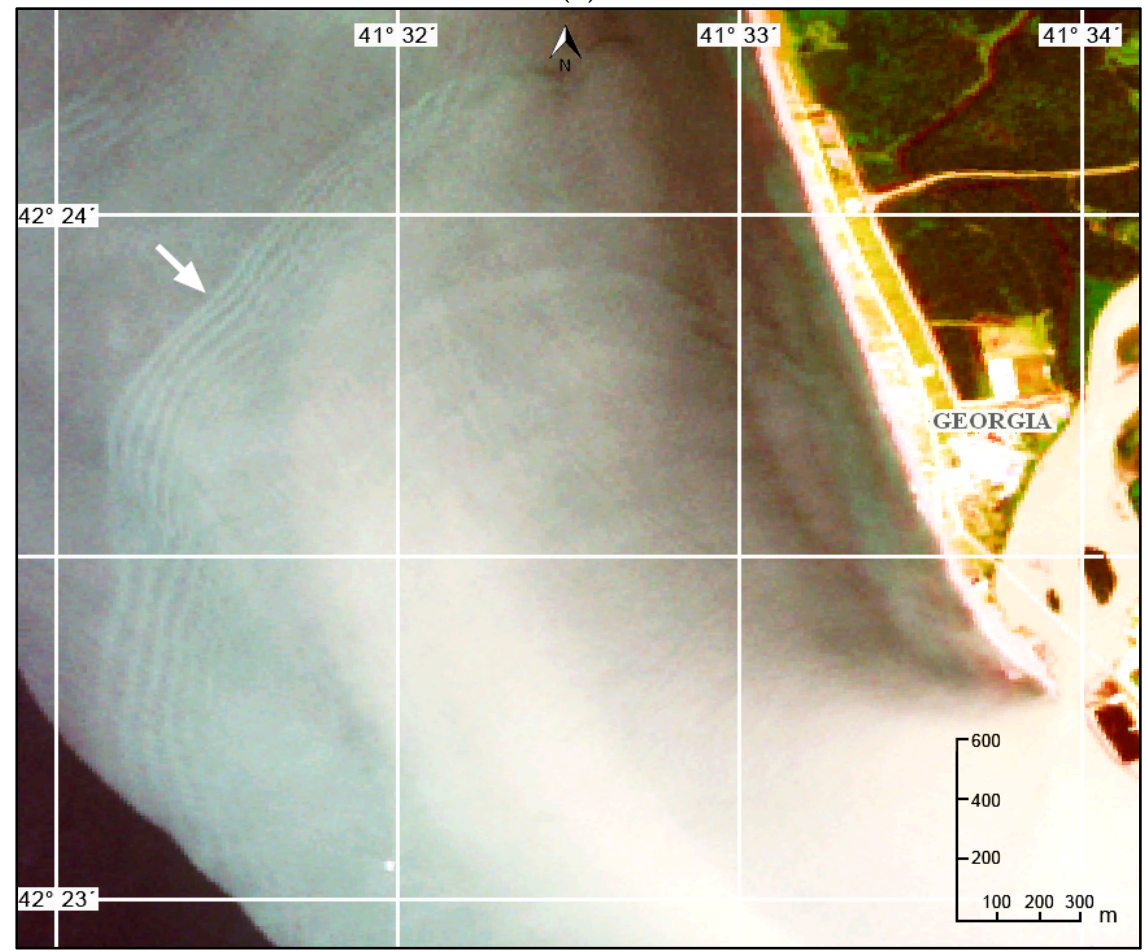

(b)

Figure 13. SMIWs in the eastern Black Sea due to river plumes of: (a) the Bzyp River, Sentinel-2A MSI, 1 May 2017; and (b) the Enguri River, Sentinel-2A MSI, 1 August 2016.

\subsubsection{IWs in the Northeastern Black Sea}

SMIWs in radar imagery of the northeastern Black Sea are scarce. We observed only fifteen instances in satellite surveys of 2005-2016. Six cases were registered in 2006, of them four in June and two in July. One SMIW was registered in August 2007, one case in June 2009, and none in years 2008 and 2010. Four SMIWs were revealed in July 2011. The 2012-2014 data gap was due to the interruption of the continuous SAR data flow (Envisat out of operation, Sentinel not launched yet). After the launch of the Sentinel satellites, we continued radar survey of the area and detected two SMIWs in June 2015 
and one in June 2016. The reasons for such a considerable interannual variability in SMIWs in radar images are discussed in Section 5.1.

Spatial distribution of SMIWs identified in radar data in the northeastern Black Sea is depicted in Figure 14.

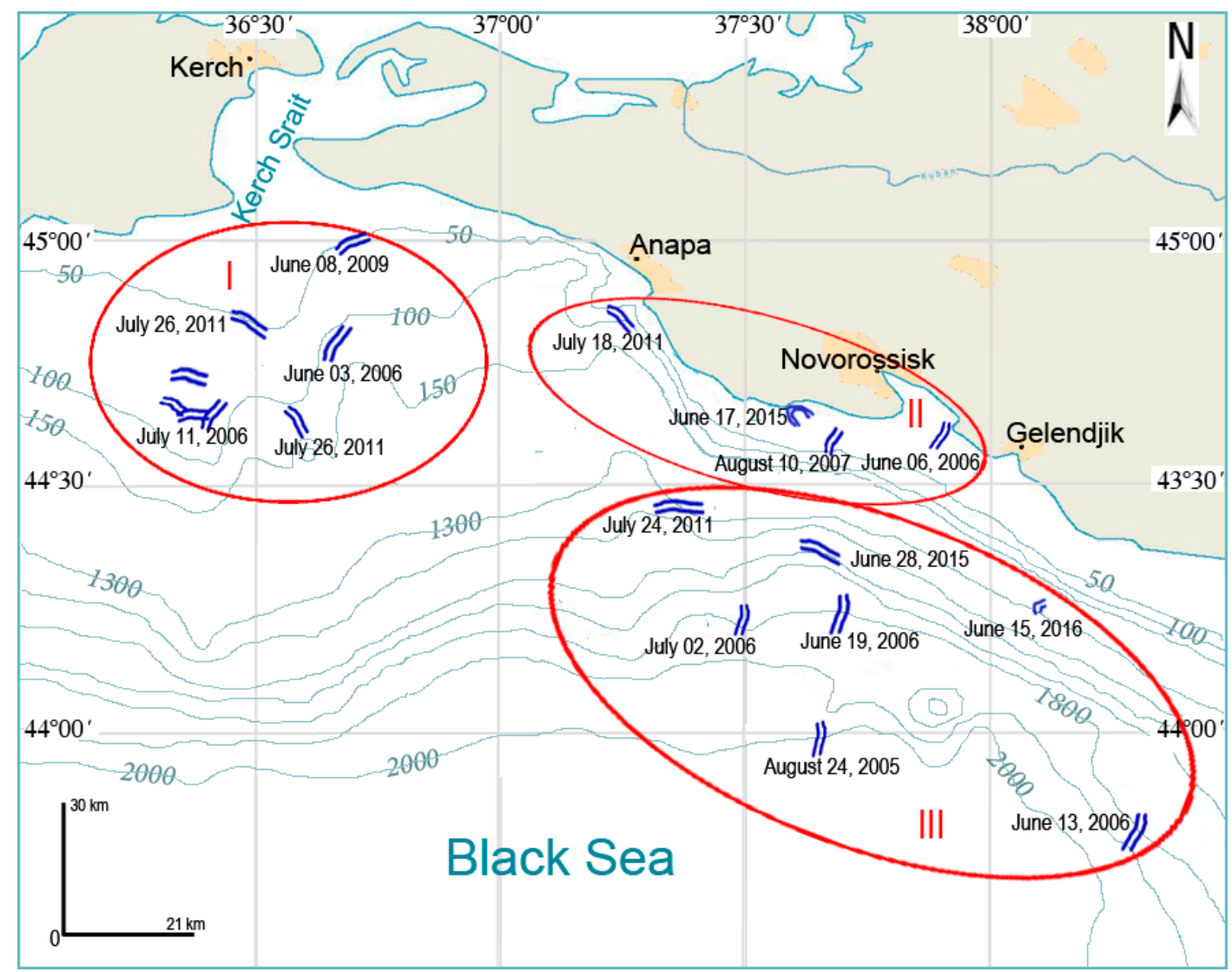

Figure 14. A map of SMIWs detected in SAR images of the northeastern Black Sea.

According to Figure 14, we can outline three regions where IWs are observed:

I. Area near the Kerch Strait between isobaths 50 and $150 \mathrm{~m}$.

II. Area near the Anapa-Gelendjik coastal line.

III. Area $45-50 \mathrm{~km}$ southwest off the Novorossiisk-Tuapse coastline between isobaths 1300 and $2000 \mathrm{~m}$.

In the northeastern Black Sea, IWs are manifested as trains containing up to 20 waves with maximal wave length in a train not exceeding $500 \mathrm{~m}$. Leading wave crest is typically substantially curved and its length varies between 7 and $18 \mathrm{~km}$. Train width varies between 850 and $3500 \mathrm{~m}$ depending on the number of waves in train. The distribution of IWs spatial characteristics derived in radar images of this region is presented in Figure 15. 


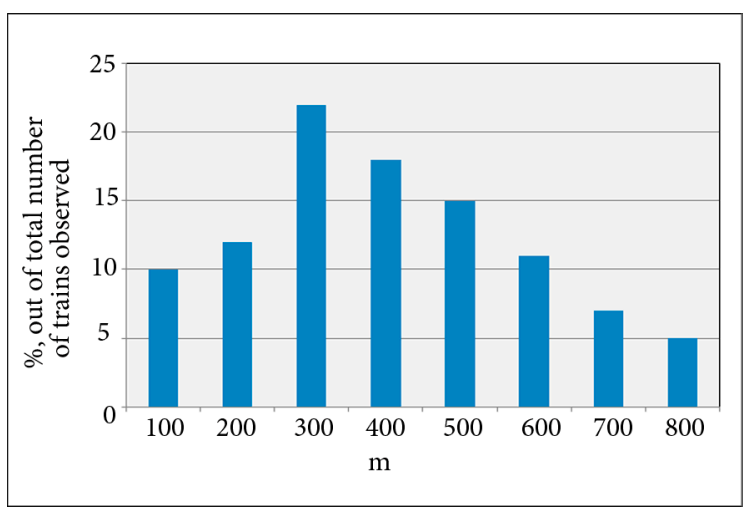

(a)

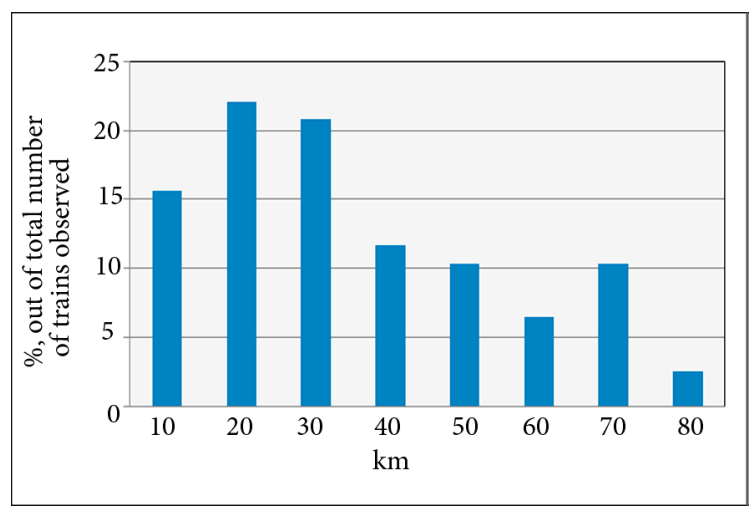

(b)

Figure 15. Distribution of spatial dimensions of IW trains detected in satellite images of the northeastern Black Sea: (a) maximal wave length; and (b) leading wave crest length.

\section{Discussion}

\subsection{Effect of Sea Water Stratification on Detectability of IWs in Radar Imagery}

The above results are evidence of a significant interannual, seasonal and spatial variability of SMIWs both at the sea surface and in radar images of the surface. Below we discuss possible reasons and show that the key factors are shape and depth of the pycnocline.

We observed a considerable interannual variability in the number of SMIWs in the northeastern Black Sea (Figure 15). Most of the SMIWs in this region were documented in 2006. To find out the reason, we analyzed the data of conductivity-temperature-depth (CTD) water column profiling performed during summer cruises of R/V Akvanavt by researchers of the South Branch of Institute of Oceanography RAS in 2006-2008. Hydrological measurements were carried out along a transection perpendicular to the coastline [62].

Figure 16 shows profiles of sea buoyancy frequency derived from CTD measurements over the depths of 1800 and $50 \mathrm{~m}$. Buoyancy frequency describes the oscillation of a water parcel about its equilibrium depth and is used as a parameter to express the strength of the seawater stratification. It is inherently related to internal gravity waves and determines an upper bound on the existence of free internal inertia-gravity waves in the sea.

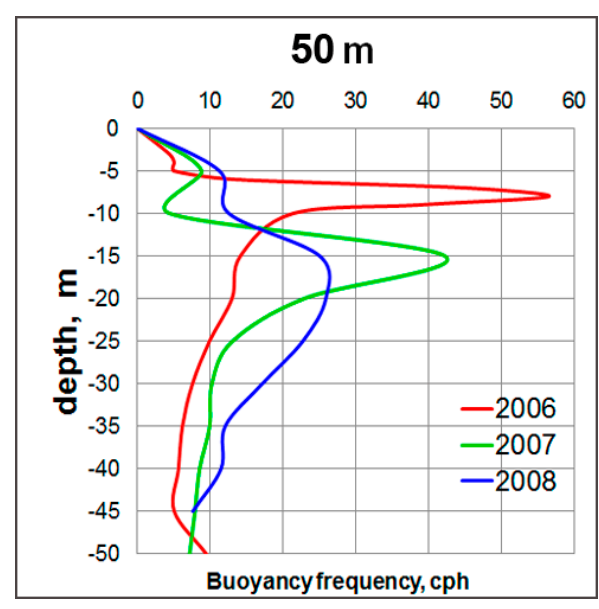

(a)

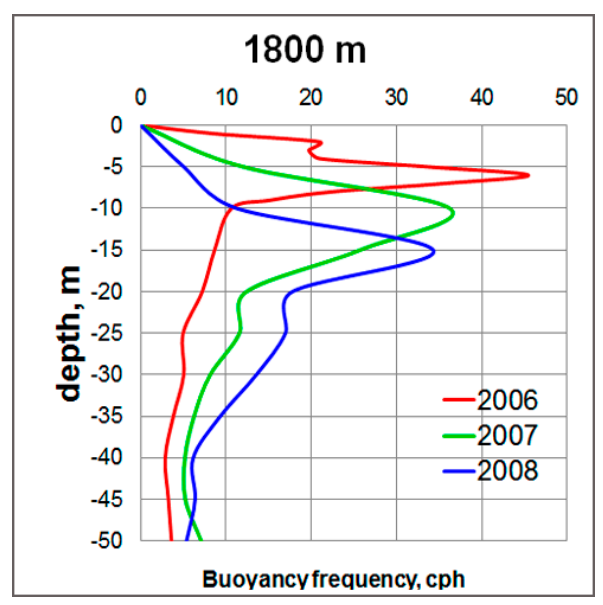

(b)

Figure 16. Vertical profiles of buoyancy frequency (cycles per hour, cph) based on in situ measurements in areas with depth of: (a) 50 m; and (b) 1800 m (northeastern Black Sea). 
The pycnocline shape of June 2006 (when most of the SMIWs were observed) has significant differences as compared to the other years, and these differences persist for different depths (Figure 16). The buoyancy frequency peak is very sharp and located at a depth of 5-7 m.

Numerous SMIWs were identified in satellite data obtained over the Caspian Sea. All were observed within the period from end of May to end of August. Three main regions of their localization depending on time were outlined. In May, SMIWs were observed on the west of South Caspian, in June and July, all SMIWs were located on the east, near the Absheron Sill, then in August, SMIWs moved north. Comparison of satellite data and in situ measurements has demonstrated (Figure 6) that the observed seasonal variability of SMIWs can also be explained by variations in pycnocline properties. Periods of numerous SMIWs coincide with seasonal thermocline formation periods. Most SMIWs registered in Middle Caspian are associated with sharp and shallow pycnocline. In summer, salinity is almost constant across all depths in Middle and South Caspian, so density gradient primarily depends on temperature gradient. As upper water layer warms up starting the second half of July, and thermocline deepens down to bottom, SMIW localization areas shift northeast, where a noticeable stratification exists.

Based on the results obtained for the northeastern Black Sea and Caspian Sea, we can state that the maximal number of SMIWs is associated with the most sharp and shallow pycnocline. Such conditions favor both generation of IWs and their manifestation at the sea surface by inducing strong orbital motions in the near-surface water layer which modulate the wind wave spectrum to produce SMIWs in radar data.

It should be noted that all SMIWs were detected in satellite data taken over Middle and South Caspian. North Caspian is the shallowest area of the sea with average depth of only $6 \mathrm{~m}$. Its depth does not exceed $10 \mathrm{~m}$ and almost $20 \%$ of the region is less than $1 \mathrm{~m}$ deep. There is no thermal stratification in North Caspian due to its shallowness. This fact explains the absence of SMIWs in this area.

\subsection{Predominating Mechanisms of IW Generation in Inner Seas}

The origins of IWs are diverse: tides, inertial oscillations, variations of atmospheric pressure and wind, earthquakes beneath the sea, currents flowing over sea floor irregularities, anthropogenic effects, etc. [61,63]. In coastal regions of oceans and tidal seas, IWs induced by interaction of tides with shelf edge prevail. By contrast, IWs in non-tidal basins, though much less intense, vary significantly by their generation mechanisms.

The main feature of IWs in non-tidal sea is their moderate amplitudes as compared to IWs in the ocean. Widely spread nonlinear effects are another characteristic of IWs on the shelf of non-tidal sea, the same as in seas with tides. Nonlinearity (vertical and horizontal profile asymmetry) of IWs is manifested in train forming intense waves, generated under certain conditions. These are a combination of processes responsible for generation of intense IWs in non-tidal sea. Previous results were based on in-situ observations from stationary platforms in the Caspian and Black Seas $[59,64]$. They enabled estimating some IW characteristics, their amplitudes and periods in the first place, and determine the corresponding hydrological conditions. However, local in situ measurements, even using a network of distributed probes, could not provide a comprehensive spatial picture and spatial characteristics of IWs in the Black and Caspian Seas, therefore limiting our outlook with regard to their origin. A complex analysis of multi-year satellite data complemented by meteorological and in-situ data, both reported in literature [16,54] and our own [24], yielded statistically valid conclusions on IW generation mechanisms in the studied seas. The results maintain that an effective generation mechanism of intense SMIWs in non-tidal sea is the intrusion of long IWs-internal seiches or quasi-inertial IWs-onto shelf that usually occurs after storms. Entering the shelf zone, long IWs play the same role in non-tidal sea as tides on ocean shelf (Section 4.2.1). On the way toward the coast, they first transform from sinusoidal to nonlinear, and then generate IW trains. In the case of a narrow shelf and abrupt continental slope (like in the Black Sea on the northeast and off the southern tip of Crimea), IWs generation is associated with surge-induced local fronts in the coastal area that are observed in periods of wind relaxation and 
restoration of water stratification disturbed by the surge (Section 4.2.2). In the case of a wide shelf (the Danube Delta region), intense IWs can be generated by a developing surface intrusion of fresh coastal waters (Sections 4.2.1 and 4.2.3).

Our long-term satellite survey revealed that practically all IW trains identified in satellite imagery of the northeastern Black Sea (Figure 14) are located close to a cold eddy structure or a cold hydrological front. This evidences in favor of the frontal generation mechanism, when IWs are radiated by a non-stationary (moving and/or inertially oscillating) front or edge of a mesoscale eddy.

I. IWs in the Black Sea area adjacent to the Kerch Strait are often generated by moving hydrological fronts. The Kerch Strait water exchange with the Black Sea is determined by the wind flows over the strait. The water level slopes from the Black to the Azov Sea under the impact of the winds blowing from the south. Under south winds, a front of salty and cold Black Sea waters can form and move towards the Kerch Strait. In satellite images, we often see SMIWs moving ahead of the front. A typical example of SMIWs generated by a cold seawater front and moving ahead of it is shown in Figure 17. This figure presents an SST chart derived from NOAA AVHRR data taken at a relatively close time to the moment of ASAR image acquisition. A thermal front separating two water masses is clearly seen. The red rectangle marks the location of IW trains propagating ahead of the front above the depths of 50-70 m. Each IW train in the Envisat ASAR image contains more than 10 waves with an average wave length of 300-400 m. The IWs trains interact nonlinearly. The SMIWs pattern is similar to tidal seas. However, these IWs are smaller in dimensions and considerably less intense in comparison to IWs in oceans and tidal seas.

II. In near-coastal waters (Region II), IW generation can be attributed to a storm surge or relaxation of upwelling.

III. Combined analysis of radar and VIS/NIR data obtained within a small time interval shows that all SMIWs revealed over deep waters (Region III) are located near the edge of a mesoscale eddy or an eddy dipole.

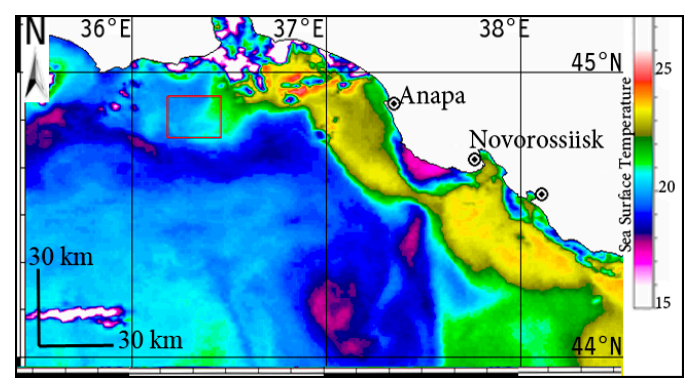

(a)

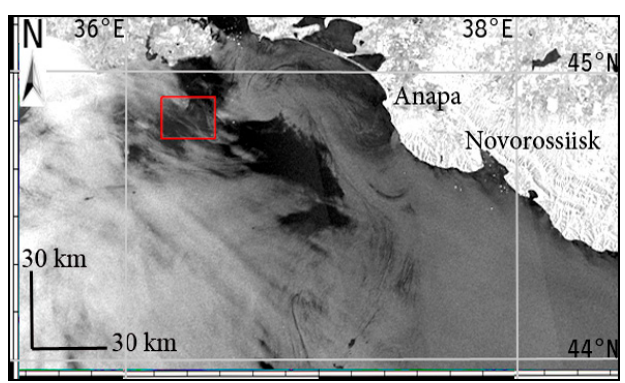

(b)

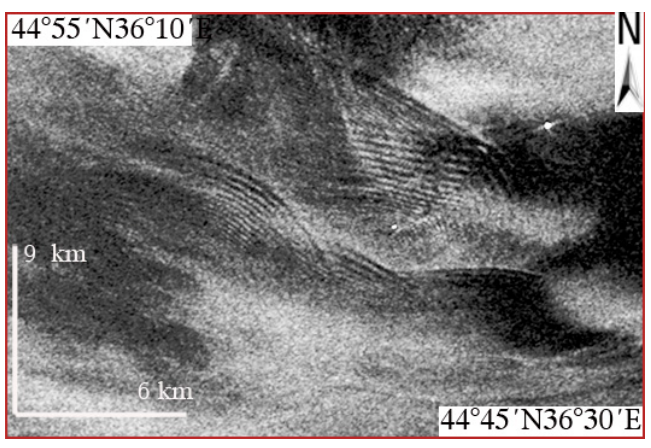

(c)

Figure 17. (a) Sea surface temperature chart from NOAA-15 data of 11 July 2006, 03:21 UTC; (b) Envisat ASAR, VV-polarization, image of 11 July 2006, 19:19 UTC; and (c) signatures of non-tidal IWs (zoom into red box in (b)). 
Figure 18 presents an Envisat ASAR image acquired on 19 June 2006 at 19:10 UTC together with a water-leaving radiance chart derived from Aqua MODIS data obtained at a close time. Dark bands distinctly visible in the Envisat ASAR image correspond to the outer boundary of an eddy dipole visualized in the water-leaving radiance chart. In the Envisat ASAR image, the boundary is visible due to filamentary biogenic films accumulated in convergence zones of the surface water layer. Maximum contrasts delineate the eddy boundary in the water-leaving radiance chart. The SMIW detectable in the Envisat ASAR image is located close to the area of high contrast. The train consisting of over 20 waves with fronts parallel to the dipole jet propagates seaward at an angle to the shore. Most probably, the IW train is radiated by the oscillating dipole jet.

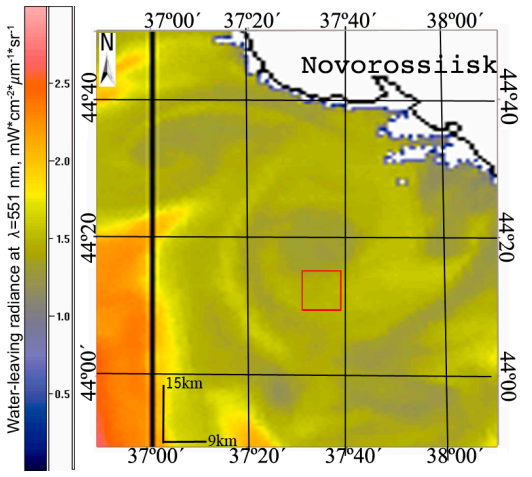

(a)

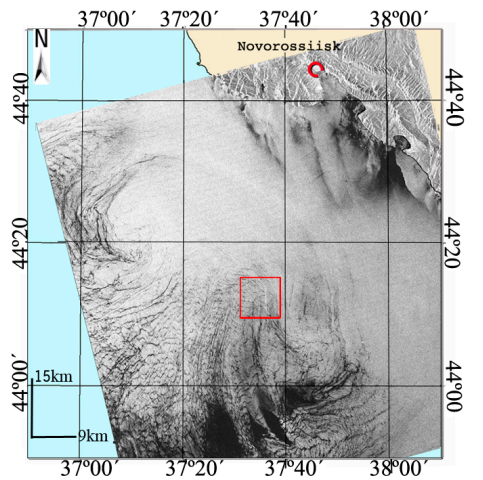

(b)

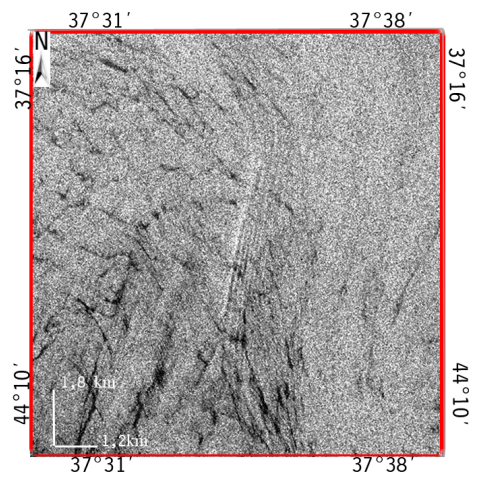

(c)

Figure 18. (a) Water-leaving radiance chart from Aqua MODIS data, wavelength $551 \mathrm{~nm}$, 20 June 2006, 11:10 UTC; (b) mesoscale eddy dipole, Envisat ASAR, VV-polarization, 19 June 2006, 19:10 UTC; and (c) signature of non-tidal IWs located in close proximity to the central part of the eddy dipole (zoom into red box in (b). There are over 20 waves in the train. Leading wave crest length is $5600 \mathrm{~m}$. Maximal wave length is $220 \mathrm{~m}$. IWs propagate seaward at an angle to the coast with fronts parallel to the dipole jet.

As to the Caspian Sea, we can point out two of the most common sources of IW generation: (i) summer upwelling often observed near the east coast; and (ii) one-node seiches with nodes situated near Absheron Cape.

Summer upwelling plays a very important role for the Caspian Sea, radically changing water dynamics. It is observed every year along the east coast of Middle and parts of South Caspian. The rise of cold deep waters occurs when strong southeast winds set to push warm surface waters away from the coast. As a result, surface temperature decreases, horizontal temperature gradients reach $2.3^{\circ} \mathrm{C}$ at the surface and $4.2{ }^{\circ} \mathrm{C}$ at a depth of $20 \mathrm{~m}$. The center of the upwelling gradually moves from $41^{\circ}-42^{\circ} \mathrm{N}$ in June to $43^{\circ}-45^{\circ} \mathrm{N}$ in September.

Seiches occur as a result of rapid changes in atmospheric or wind pressure over the sea surface. Free seiche oscillations arise in Middle and South Caspian with predominating periods of 8.5-8.7 and 4.2-4.6 h. The nodal line of a longitudinal uninodal seiche extends approximately along the Absheron Sill separating Middle and South Caspian. Strong seiche currents bumping against the steep slope generate thermocline oscillations inducing IWs. The sill-formed IWs radiate to deeper sea, less affected by the bathymetry.

\subsection{IWs and Look-Alikes in Non-Tidal Seas}

Study of IWs in non-tidal seas based on satellite data is a complicated task. One of non-trivial problems is discrimination between the signatures of IWs generated in water and in the atmosphere above the sea surface.

Atmospheric internal gravity waves (AIWs) propagate all the time and everywhere in a stratified atmosphere. They have various origins: air flows past different obstacles generating so-called lee 
waves, interaction of continental and marine air masses, movement of cold atmospheric fronts, etc. In radar images of sea surface, we can observe AIWs when wind variations modulate sea surface roughness so as it results in backscatter modulation [65].

Radar signatures of oceanic IWs (OIWs) and AIWs are frequently confused. Both are shaped in alternating bands of enhanced and attenuated radar backscatter, similar in intensity. It is easier to discriminate them in regions where OIWs are generated by tides at shelf edge. Such OIWs have typical signatures of trains, as a rule, propagating toward the coast. Their localization and seasonal variability are well known [4]. Radar signatures of OIWs have high contrasts; bands of enhanced backscatter are extremely narrow, not more than 2-3 pixels (pixel resolution $75 \mathrm{~m}$ ). Usually, AIWs propagate away from the coast (orography waves), or on the lee side of islands, or are associated with passage of an atmospheric front. AIWs have greater spatial dimensions: front lengths reach 200-300 km and more, wave lengths are seldom less than 1-2 km. However, our satellite monitoring shows that in inner seas, such as the Black and Caspian Seas, AIWs are manifested in a variety of patterns: from gigantic narrow solitary waves with front length reaching $600 \mathrm{~km}$ to small-scale trains containing more than 10 waves. Sometimes, the latter are very hard to differentiate from OIWs. An example is shown in Figure 19. Radar signatures of OIWs and AIWs are very similar here, but some distinctions are quite noticeable. OIWs are manifested as bright bands (suloys) with curved fronts (Figure 19a), while AIWs as parallel dark bands (slicks) (Figure 19b). Given the same resolution of both images $(75 \mathrm{~m})$, the suloys are narrower than the slicks. The signatures of AIWs appear less sharp, which is confirmed by the inset graphs of normalized radar cross section (NRCS) along the black lines.

Obviously, to reliably discriminate between OIWs and AIWs in enclosed non-tidal seas, in addition to comparing radar contrasts and spatial properties, we need to consider all available hydrometeorological information, data on sea surface state, sea floor bathymetry and coastal orography. The best approach would be to employ atmospheric sounding and compute the Scorer parameter, as it was made in [66]. Unfortunately, radiosonde observations are hardly affordable for most researchers. At present, the final decision is up to the human expert who analyzes radar data and all complementary information. The problem of discriminating surface manifestations of OIWs and AIWs in radar imagery is certainly a topic of an individual comprehensive consideration and cannot be examined within the present work, it is only mentioned here for the sake of completeness of the presentation. A detailed discussion of discrimination between OIWs and AIWs in radar data can be found in [67]. Despite the fact that the paper considers seas with tides, the principal conclusions agree with our results: the main discrimination criteria are based on the shape and structure of radar signatures. The authors also present useful findings on polarization differences of the signatures. AIWs are better pronounced in $\mathrm{HH}$ polarization and OIWs in VV polarization. We plan to further investigate this aspect based on radar observations of the Caspian Sea, where, unlike the Black Sea, OIW are frequently manifested.

Another problem of SMIWs studies is their differentiating from fine current structures within submesoscale eddies. It is well known that, in radar images, submesoscale eddies are primarily visualized by slicks $[25,68]$. At eddy edges, however, slicks may be shaped in quasi periodic structures similar to IW trains.

We hope that, with the Sentinel program in place, the steady flow of high resolution radar data that the sensors provide will facilitate important advances in the study of such infrequent phenomenon as IWs in non-tidal seas. 


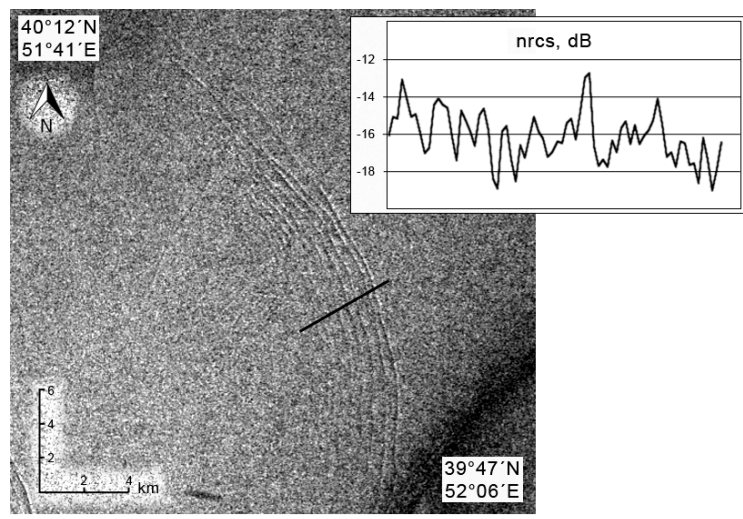

(a)

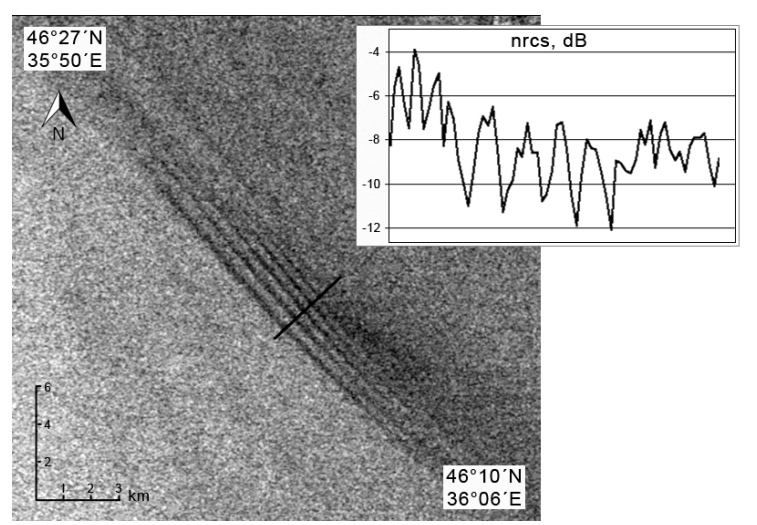

(b)

Figure 19. Comparison of radar signatures of OIW and AIW: (a) OIW, Envisat ASAR, HH-polarization, 24 July 2009; and (b) AIW, Envisat ASAR, VV-polarization, 14 March 2009. The inset graphs show variations in radar signal along the cross sections of the trains (black lines).

\section{Conclusions}

We present results of our study of SMIWs in the Black and Caspian Seas. In these seas, no significant tides can ever develop, so they can be considered non-tidal. Consequently, the main mechanism of IW generation in ocean-interaction of tidal wave with bathymetry-is irrelevant.

Analysis of satellite data, primarily radar imagery (ERS-2 SAR, Envisat ASAR, and Sentinel-1 SAR-C) allowed us to identify regions of most regular SMIWs in these seas. In the Black Sea, there are four such regions: (I) near the Danube Delta on the northwest; (II) near the Crimean Peninsula; (III) near the city of Novorossiysk on the northeast; and (IV) the shelf of Georgia on the east. In the Caspian Sea, SMIWs have distinct seasonal variability. In the end of May and in the first half of June, SMIWs can be found only in the western part of South Caspian (I); in the second part of June and in July, all SMIWs are observed on the east, near the Absheron Sill (II); and, in August, they appear northeast of the Absheron Sill (III).

A comparative analysis of the observed non-tidal IWs was performed. A strong diversity of SMIW forms, propagation directions and types of surface wave modulation was revealed which implied different mechanisms of IW generation. For each region of regular SMIWs, the factors facilitating generation of non-tidal IWs were identified via joint analysis of radar, VIS and NIR satellite data and corresponding hydrometeorological information. For instance, in the eastern and western coastal zones of the Black Sea, where large rivers disembogue, intrusions of fresh water create hydrological fronts able to generate IWs. At continental shelf edge, on the west and northwest of the Black Sea and near Crimea, the main IW generation mechanisms are: relaxation of coastal upwelling, inertial oscillations associated with hydrological fronts, and storm surges. For the first time, we discovered IWs formed at the fronts associated with passage of cold eddies. Processes of the type we observed several times in the northwestern Black Sea. In the Caspian Sea, seiches were the main source of IWs that we observed in satellite images.

The relation between occurrence of SMIWs and position of the pycnocline peak was also established. Sharp and shallow pycnocline was shown to facilitate generation of IWs as well as enhance near-surface currents associated with IWs.

In conclusion, we should note that statistically significant estimates of spatial and temporal distribution of surface manifestations of non-tidal IWs in the Black and Caspian Seas have been obtained for the first time. 
Acknowledgments: This research is supported by the Russian Science Foundation under the project \# 14-17-00555. Basic functionality of the STS portal is implemented in frame of Theme "Monitoring", state register No. 01.20.0.2.00164 (FASO Russia). The authors are grateful to late Konstantin D. Sabinin for useful discussions and help in investigating SMIWs, to Andrey N. Serebryany for help in IW nonlinearity calculations (both from N.N. Andreev Acoustics Institute, Moscow, Russia) and to Tatiana Yu. Bocharova (Space Research Institute, Moscow, Russia) for the assistance in satellite data processing. We would like to thank two anonymous reviewers for their valuable comments and suggestions.

Author Contributions: Both authors contributed equally to the paper. Olga Lavrova and Marina Mityagina analyzed data, contributed with ideas and discussions, and wrote the manuscript.

Conflicts of Interest: The authors declare no conflict of interest.

\section{References}

1. LeBlond, P.H.; Mysak, L.A. Waves in the Ocean; Elsevier: Amsterdam, The Netherlands, 1978; pp. 1-602.

2. Hughes, B.A. The effect of internal waves on surface wind waves. 2. Theoretical analysis. J. Geophys. Res. 1978, 83, 455-469. [CrossRef]

3. Alpers, W.; Salusti, E. Scylla and Charybdis observed from space. J. Geophys. Res. 1983, 88, 1800-1808. [CrossRef]

4. Jackson, C.; Apel, J. An Atlas of Internal Solitary-like Waves and their Properties. Second Edition. Available online: http:/ / www.internalwaveatlas.com/Atlas2_index.html (accessed on 22 June 2017).

5. Zhao, Z.; Liu, B.; Li, X. Internal solitary waves in the China seas observed using remote-sensing techniques: A review and perspectives. Int. J. Remote Sens. 2014, 35, 3926-3946. [CrossRef]

6. Klemas, V. Remote sensing of ocean internal waves: An overview. J. Coast. Res. 2012, 28, 540-546. [CrossRef]

7. Prasad, K.; Rajasekhar, M. Space borne SAR observations of oceanic internal waves in North Bay of Bengal. Nat. Hazards 2011, 57, 657-667. [CrossRef]

8. Lorenzzetti, J.A.; Dias, F.G. Internal solitary waves in the Brazilian SE continental shelf: Observations by synthetic aperture radar. Int. J. Oceanogr. 2013, 2013, 403259. [CrossRef]

9. Da Silva, J.C.B.; New, A.L.; Magalhaes, J.M. On the structure and propagation of internal solitary waves generated at the Mascarene Plateau in the Indian Ocean. Deep Sea Res. I 2011, 58, 229-240. [CrossRef]

10. Da Silva, J.C.B.; Buijsman, M.C.; Magalhaes, J.M. Internal waves on the upstream side of a large sill of the Mascarene Ridge: A comprehensive view of their generation mechanisms and evolution. Deep Sea Res. I 2015, 99, 87-104. [CrossRef]

11. Hyder, P.; Jeans, D.R.G.; Cauquil, E.; Nerzic, R. Observations and predictability of internal solitons in the Northern Andaman Sea. Appl. Ocean Res. 2005, 27, 1-11. [CrossRef]

12. Alpers, W.; Brandt, P.; Rubino, A. Internal Waves Generated in the Straits of Gibraltar and Messina: Observations from Space. In Remote Sensing of the European Seas; Barale, V., Gade, M., Eds.; Springer: Heidelberg, Germany, 2008; pp. 319-330.

13. Susanto, R.D.; Mitnik, L.; Zheng, Q. Ocean internal waves observed in the Lombok Strait. Oceanography 2005, 18, 80-87. [CrossRef]

14. Liu, A.K.; Su, F.C.; Hsu, M.K.; Kuo, N.J.; Ho, C.R. Generation and evolution of mode-two internal waves in the South China Sea. Cont. Shelf Res. 2013, 59, 18-27. [CrossRef]

15. Li, X.; Jackson, C.R.; Pichel, W.G. Internal solitary wave refraction at Dongsha Atoll, South China Sea. Geophys. Res. Lett. 2013, 40, 3128-3132. [CrossRef]

16. Ivanov, V.A.; Serebryany, A.N. Short-period internal waves in the coastal zone of a non-tidal sea. Izv. Atmos. Ocean. Phys. 1985, 21, 648-656.

17. Vlasenko, V.I.; Ivanov, V.A.; Krasin, I.G.; Lisichenok, A.D. Generation of intense short-period internal waves in the Crimean shelf zone during an event of coastal upwelling. Mar. Hydrophys. J. 1997, 3, 3-16.

18. Bidokhti, A.A.; Shekarbaghani, A. The role of internal waves in the formation of layered structure at exchange flows between two closed basins (Middle and southern basins of the Caspian Sea). Iran. J. Phys. Res. 2006, 5, 99-104.

19. Filatov, N.; Terzevik, A.; Zdorovennov, R.; Vlasenko, V.; Stashchuk, N.; Hutter, K. Field Studies of Non-Linear Internal Waves in Lakes on the Globe. In Nonlinear Internal Waves in Lakes; Hutter, K., Ed.; Springer: Berlin, Germany, 2012; pp. 23-103. 
20. Ivanov, A.Y.; Alpers, W.; Naumenko, M.A.; Karetnikov, S.G. Lake Ladoga surface features on the ERS-1 SAR imagery. In ESA SP-414, Proceedings of the 3rd ERS Symposium, Florence, Italy, 14-21 March 1997; ESA Publications Division: Noordwijk, The Netherlands, 1997; pp. 1035-1040.

21. Lavrova, O.Y.; Kostianoy, A.G.; Lebedev, S.A.; Mityagina, M.I.; Ginzburg, A.I.; Sheremet, N.A. Complex Satellite Monitoring of the Russian Seas; IKI RAN: Moscow, Russia, 2011. (In Russian)

22. Mityagina, M.; Lavrova, O. Surface manifestations of non-tidal internal waves in the North-Eastern Black Sea as viewed by satellite sensors. In Proceedings of the 2009 IEEE International Geoscience and Remote Sensing Symposium (IGARSS'09), Cape Town, South Africa, 12-17 July 2009.

23. Mityagina, M.I.; Lavrova, O.Y.; Karimova, S.S. Multi-sensor survey of seasonal variability in coastal eddy and internal wave signatures in the north-eastern Black Sea. Int. J. Remote Sens. 2010, 31, 4779-4790. [CrossRef]

24. Lavrova, O.Y.; Mityagina, M.I.; Serebryany, A.N.; Sabinin, K.D.; Kalashnikova, N.A.; Krayushkin, E.V.; Khymchenko, I. Internal waves in the Black Sea: Satellite observations and in-situ measurements. In Proceedings of the Remote Sensing of the Ocean, Sea Ice, Coastal Waters, and Large Water Regions 2014, Amsterdam, The Netherlands, 14 October 2014; Volume 9240.

25. Lavrova, O.Y.; Mityagina, M.I.; Sabinin, K.D.; Serebryany, A.N. Study of hydrodynamic processes in the shelf zone based on satellite data and subsatellite measurements. Sovremennye Problemy Distantsionnogo Zondirovaniya Zemli iz Kosmosa 2015, 12, 98-129. (In Russian)

26. Medvedev, I.P.; Rabinovich, A.B.; Kulikov, E.A. Tides in Three Enclosed Basins: The Baltic, Black, and Caspian Seas. Front. Mar. Sci. 2016, 3, 1-7. [CrossRef]

27. Kostianoy, A.G.; Kosarev, A.N. (Eds.) The Caspian Sea Environment. The Handbook of Environmental Chemistry. Water Pollution, Part P; Springer: Berlin/Heidelberg, Germany; New York, NY, USA, 2000; Volume 5, p. 271.

28. Medvedev, I.P.; Kulikov, E.A.; Rabinovich, A.B. Tidal Oscillations in the Caspian Sea. Oceanology 2017, 57, 360-375. [CrossRef]

29. Gunduz, M. Caspian Sea surface circulation variability inferred from satellite altimeter and sea surface temperature. J. Geophys. Res. 2014, 119, 1420-1430. [CrossRef]

30. Grinevetskiy, S.R.; Zonn, I.S.; Zhiltsov, S.S.; Kosarev, A.N.; Kostianoy, A.G. The Black Sea Encyclopedia; Springer: Berlin/Heidelberg, Germany; New York, NY, USA, 2015; p. 889.

31. Oguz, T.; Latun, V.S.; Latif, M.A.; Vladimirov, V.; Su, H.; Markov, A.; Ozsoy, E.; Kotovshchikov, B.; Eremeev, V.; Unluata, U. Circulation in surface and intermediate layers of the Black Sea. Deep Sea Res. I 1993, 40, 1597-1612. [CrossRef]

32. Stanev, E. Understanding Black Sea dynamics. An Overview of Recent Numerical Modeling. Oceanography 2005, 18, 56-75. [CrossRef]

33. Zatsepin, A.G.; Ginzburg, A.I.; Kostianoy, A.G.; Kremenetskiy, V.V.; Krivosheya, V.G.; Stanichny, S.V.; Poulain, P.M. Observations of Black Sea Mesoscale Eddies and Associated Horizontal Mixing. J. Geophys. Res. 2003, 108, 3246. [CrossRef]

34. Zatsepin, A.G.; Kremenetskiy, V.V.; Ostrovskii, A.G.; Baranov, V.I.; Kondrashov, A.A.; Korzh, A.O.; Soloviev, D.M. Submesoscale eddies at the Caucasus Black Sea shelf and the mechanisms of their generation. Oceanology 2011, 51, 554-567. [CrossRef]

35. Korotaev, G.K.; Oguz, T.; Nikiforov, A.; Koblinsky, C. Seasonal, interannual, and mesoscale variability of the Black Sea upper layer circulation derived from altimeter data. J. Geophys. Res. 2003, 108, 3122. [CrossRef]

36. Loupian, E.A.; Matveev, A.A.; Uvarov, I.A.; Bocharova, T.Y.; Lavrova, O.Y.; Mityagina, M.I. The satellite service See the Sea-A tool for the study of oceanic phenomena and processes. Sovremennye Problemy Distantsionnogo Zondirovaniya Zemli iz Kosmosa 2012, 9, 251-261. (In Russian)

37. Mityagina, M.I.; Lavrova, O.Y.; Uvarov, I.A. See the Sea: Multi-user information system for investigating processes and phenomena in coastal zones via satellite remotely sensed data, particularly hyperspectral data. In Proceedings of the SPIE 9240, Remote Sensing of the Ocean, Sea Ice, Coastal Waters, and Large Water Regions 2014, Amsterdam, The Netherlands, 22 September 2014.

38. Lighthill, M.J. Waves in Fluids, 1st ed.; Cambridge University Press: Cambridge, UK, 1978.

39. Alpers, W. Theory of radar imaging of internal waves. Nature 1985, 314, 245-247. [CrossRef]

40. Apel, J.R.; Gasparovic, R.F.; Thompson, D.R.; Gotwols, B.L. Signatures of Surface Wave/Internal Wave Interactions: Experiment and Theory. Dyn. Atmos. Oceans 1988, 12, 89-106. [CrossRef]

41. Gade, M.; Alpers, W.; Ermakov, S.A.; Hühnerfuss, H.; Lange, P.A. Wind-wave tank measurements of bound and freely propagating short gravity-capillary waves. J. Geophys. Res. 1998, 103, 21697-21710. [CrossRef] 
42. Ebuchi, N.; Kawamura, H.; Toba, Y. Fine structure of laboratory wind-wave surfaces studied using an optical method. Bound. Layer Meteorol. 1987, 39, 133-151. [CrossRef]

43. Gorshkov, K.A.; Dolina, I.S.; Soustova, I.A.; Troitskaya, Y.I. Modulation of short wind waves in the presence of strong internal waves: The effect of growth-rate modulation. Izv. Atmos. Ocean. Phys. 2003, 39, 596-606.

44. Churyumov, A.N.; Kravtsov, Y.A.; Lavrova, O.Y.; Litovchenko, K.T.; Mityagina, M.I.; Sabinin, K.D. Signatures of resonant and non-resonant scattering mechanisms on radar images of internal waves. Int. J. Remote Sens. 2002, 23, 4341-4355. [CrossRef]

45. Kravtsov, Y.A.; Mityagina, M.I.; Churyumov, A.N. Electromagnetic waves backscattering by mesoscale breaking waves on the sea surface. Uspekhi Fizicheskikh Nauk 1999, 63, 1859-1865.

46. Voronovich, A.G.; Zavorotny, V.U. Theoretical model for scattering of radar signals in Ku- and C-bands from a rough sea surface with breaking waves. Wave Random Media 2001, 11, 247-269. [CrossRef]

47. Kudryavtsev, V.; Akimov, D.; Johannessen, J.; Chapron, B. On radar imaging of current features: 1. Model and comparison with observations. J. Geophys. Res. Oceans 2005, 110, 691-706. [CrossRef]

48. Ermakov, S.A.; da Silva, J.C.; Robinson, I.S. The role of surface films in SAR signatures of internal waves on the shelf. II. Internal tidal waves. J. Geophys. Res. 1998, 103, 8033-8043. [CrossRef]

49. Da Silva, J.C.B.; Ermakov, S.A.; Robinson, I.S. Role of surface films in ERS SAR signatures of internal waves on the shelf: 3.Mode transitions. J. Geophys. Res. 2000, 105, 24089-24104. [CrossRef]

50. Lavrova, O.U.; Mityagina, M.I.; Sabinin, K.D.; Serebryany, A.N. Satellite Observations of Surface Manifestations of Internal Waves in the Caspian Sea. Izv. Atmos. Ocean. Phys. 2011, 47, 1119-1126. [CrossRef]

51. Nash, J.D.; Moum, J.N. River plumes as a source of large-amplitude internal waves in the coastal ocean. Nature 2005, 437, 400-403. [CrossRef] [PubMed]

52. Stashchuk, N.; Vlasenko, V. Generation of internal waves by a supercritical stratified plume. J. Geophys. Res. Oceans 2009, 114, 362-370. [CrossRef]

53. Pan, J.; Jay, D.A.; Orton, P.M. Analyses of internal solitary waves generated at the Columbia River plume front using SAR imagery. J. Geophys. Res. Oceans 2007, 112, 1835-1855. [CrossRef]

54. Ivanov, V.A.; Serebryanyi, A.N. Vnutrennie volny na melkovodnom shel'fe besprilivnogo moray. Izv. Akad. Nauk SSSR Fiz. Atmos. Okeana 1983, 19, 661-665.

55. Pao, H.P.; Serebryany, A.N. Studies of intense internal gravity waves: Field measurements and numerical modeling. In Advances in Engineering Mechanics Reflections and Outlooks; In Honor of Theodore T-Y Wu; Chuang, A.T., Teng, M.H., Valentine, D.T., Eds.; World Scientific: New Jersey, NJ, USA, 2005; pp. $286-296$.

56. Smyth, W.D.; Moum, J.N.; Nash, J.D. Narrowband oscillations in the upper equatorial ocean: Part II. Properties of shear instabilities. J. Phys. Oceanogr. 2011, 41, 412-428. [CrossRef]

57. Grimshaw, R. Korteweg de-Vries Equation. In Nonlinear Waves in Fluids: Recent Advances and Modern Applications; CISM International Centre for Mechanical Sciences: Udine, Italy, 2005; Volume 483, pp. 1-28.

58. Boegman, L. Currents in Stratified Water Bodies 2: Internal Waves. In Encyclopedia of Inland Waters; Likens, G.E., Ed.; Elsevier: Oxford, UK, 2009; Volume 1, pp. 539-558.

59. Serebryany, A.N. Nonlinearity effects in internal waves on the shelf. Izv. Akad. Nauk SSSR Fiz. Atmos. Okeana 1990, 26, 285-293.

60. Zheng, Q.; Vic Klemas, V.; Yan, X.-H.; Pan, J. Nonlinear evolution of ocean internal solitons propagating along an inhomogeneous thermocline. J. Geophys. Res. Oceans 2001, 106, 14083-14094. [CrossRef]

61. Sabinin, K.; Serebryany, A. Intense short period internal waves in the Ocean. J. Mar. Res. 2005, 63, $227-261$. [CrossRef]

62. Mityagina, M.; Lavrova, O. Comparative analysis of internal waves surface manifestations observed by Envisat ASAR in different non-tidal seas. In ESA Special Publication SP-686, Proceedings of ESA Living Planet Symposium, Bergen, Norway, 28 June-2 July 2010; Lacoste-Francis, H., Ed.; ESA Publications Division: Noordwijk, The Netherlands, 2010.

63. Jackson, C.; da Silva, J.; Jeans, G. The generation of nonlinear internal waves. Oceanography 2012, 25, 108-123. [CrossRef]

64. Serebryany, A.N. Manifestation of the properties of solitons in the internal waves on the shelf. Izv. Akad. Nauk Fiz. Atmos. Okeana 1993, 29, 244-252. 
65. Bulatov, M.G.; Kravtsov, Y.A.; Lavrova, O.Y.; Litovchenko, K.T.; Mityagina, M.I.; Raev, M.D.; Sabinin, K.D.; Trokhimovskii, Y.G.; Churyumov, A.N.; Shugan, I.V. Physical Mechanisms of Aerospace Radar Imaging of the Ocean. Uspekhi Fizicheskikh Nauk 2003, 173, 69-87. [CrossRef]

66. Da Silva, J.C.B.; Magalhaes, J.M. Satellites observations of large atmospheric gravity waves in the Mozambique Channel. Int. J. Remote Sens. 2009, 30, 1161-1182. [CrossRef]

67. Alpers, W.; Huang, W. On the discrimination of radar signatures of atmospheric gravity waves and oceanic internal waves on synthetic aperture radar images of the sea surface. IEEE Trans. Geosci. Remote Sens. 2011, 49, 1114-1126. [CrossRef]

68. Munk, W.; Armi, L.; Fisher, K.; Zachariasen, F. Spirals on the Sea. Proc. R. Soc. 2000, 456, 1217-1280. [CrossRef]

(C) 2017 by the authors. Licensee MDPI, Basel, Switzerland. This article is an open access article distributed under the terms and conditions of the Creative Commons Attribution (CC BY) license (http:/ / creativecommons.org/licenses/by/4.0/). 